\title{
THE ANALYSIS AND SIMULATION OF THE CYLINDRICAL ELECTRIC DIPOLE ANTENNA RESPONSE TO EMP
}

\author{
Paul R. Barnes
}

\section{MASTER}

OAK RIDGE NATIONAL LABORATORY

OPERATED BY UNION CARBIDE CORPORAIION - FOR THE U.S. ATOMIC ENERGY COMMISSION 


\section{DISCLAIMER}

This report was prepared as an account of work sponsored by an agency of the United States Government. Neither the United States Government nor any agency Thereof, nor any of their employees, makes any warranty, express or implied, or assumes any legal liability or responsibility for the accuracy, completeness, or usefulness of any information, apparatus, product, or process disclosed, or represents that its use would not infringe privately owned rights. Reference herein to any specific commercial product, process, or service by trade name, trademark, manufacturer, or otherwise does not necessarily constitute or imply its endorsement, recommendation, or favoring by the United States Government or any agency thereof. The views and opinions of authors expressed herein do not necessarily state or reflect those of the United States Government or any agency thereof. 


\section{DISCLAIMER}

Portions of this document may be illegible in electronic image products. Images are produced from the best available original document. 
This report was prepared as an account of work sponsored by the United States Government. Neither the United States nor the United States Atomic Energy Commission, nor any of their employees, nor any of their contractors, subcontractors, or their employees, makes any warranty, express or implied, or assumes any legal liability or responsibility for the accuracy, completeness or usefulness of any information, apparatus, product or process disclosed, or represents that its use would not infringe privately owned rights. 
Contract No. W-7405-eng-26

HEALTH PHYSICS DIVISION

THE ANALYSIS AND SIMULATION OF THE CYLINDRICAL ELECTRIC DIPOLE ANTENNNA RESPONSE TO EMP

Paul R. Barnes

\title{
SEPTEMBER 1973
}

NOTICE This document contains information of a preliminary nature and was prepared primarily for internal use at the Oak Ridge National Laboratory. It is subject to revision or correction and therefore does not represent a final report.

\author{
OAK RIDGE NATIONAL LABORATORY \\ Oak Ridge, Tennessee \\ operated by \\ UNION CARBIDE CORPORATION \\ for the \\ U.S. ATOMIC ENERGY COMMISSION
}


THIS PAGE

WAS INTENTIONALLY

LEFT BLANK 
CONTEINTS

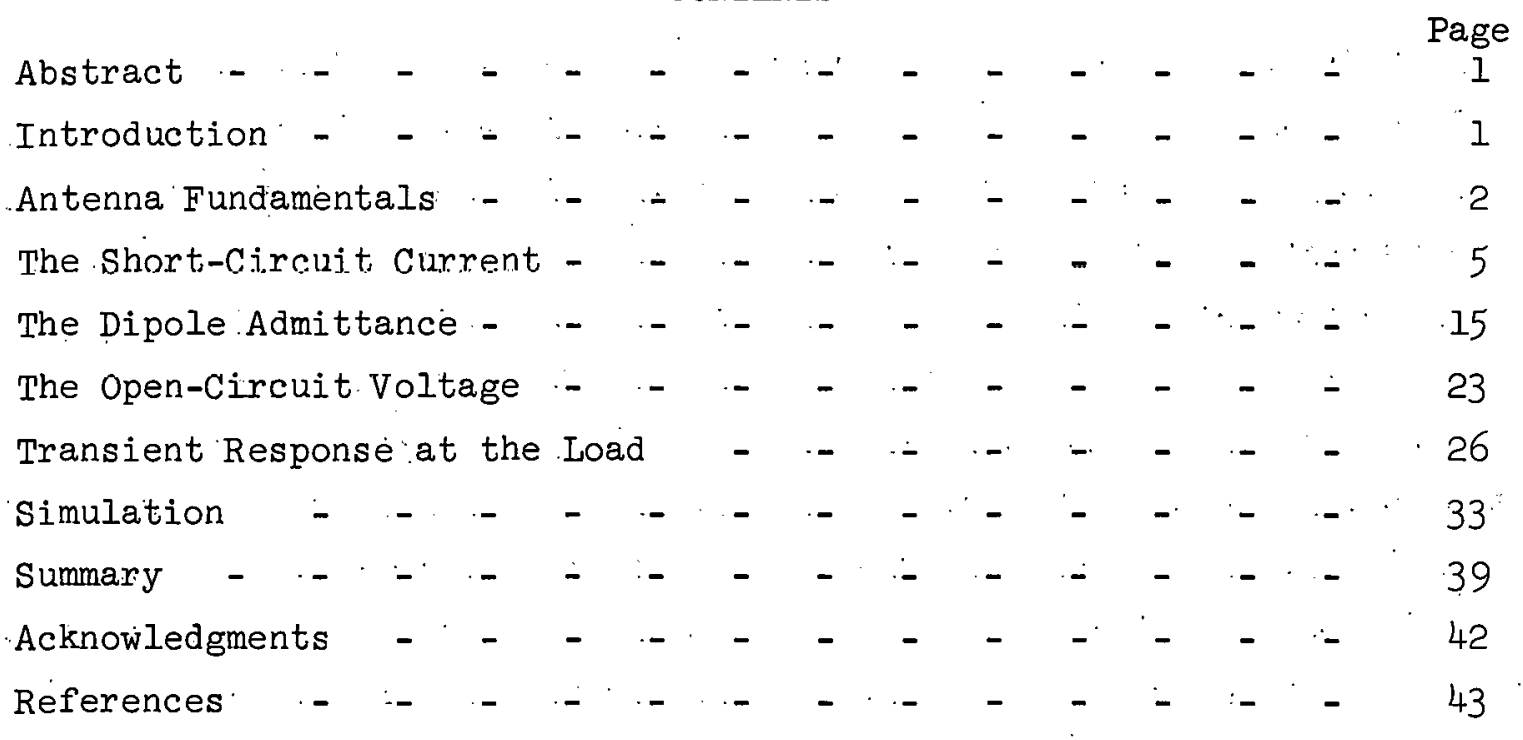




\section{FOREWORD}

This work is an effort to advance analytical solutions for the cylindrical dipole and half-dipole responses to EMP. The accuracy of. the solution depends on the accuracy of both the theoretical model and. the mathematical solution thereof. The models used to calculate the antenna short-circuit current response are straightforward and the accuracy of the solutions is determined by the number of terms considered in the singularity expansion. To determine the open-circuit voltage and the load current and voltage responses, it is necessary to use the antenna admittance. The dipole admittance expression used in this work was derived from the late-time solution for the current on a dipole excited by a source voltage across a circumferential gap of infinitesimal width.* Thus, both the model and mathematical solution are not entirely accurate. The problems associated with the admittance of a cylindrical dipole antenna excited by a delta-gap source for calculating the EMP antenna response should be further investigated. As for the mathematical solution of the dipole responses, the results obtained from the analytical solutions presented in this paper compare very well with the more complicated numerical solutions for the same physical model. The relative difference between the numerical and analytical results is only a few percent.

${ }^{*}$ A voltage across a circumferential gap of infinitesimal width is also called a "delta-gap source." 
- THE A.NALYSIS AND SIMULATION OF THE CYLTINDRICAL

ELECTR:IC DIPOLE ANTENNA RESPONSE TO EMP

Paul R. Barnes

\section{ABSTRACT}

The results of the singularity, expansion method.as applied to the electromagnetic scattering from a thin cylinder are used, in the analysis of the electric cylindrical dipole antenna response to electromagnetic pulse (EMP).... Simple analy.tical formulas are obtained . for ..the time-domain dipole short-circuit current response to incident fields wi.th a s.tep function and decaying exponential .time histories.. . Simple, analytical expressions are derived for the...dominant terms in the solutions of the antenna admittance and the time-domain dipole open-circui.t.voltage. Also, simple formulas to calculate the load. current and voltage responses are developed. For the tuned load with a first resonant equal to the antenna's first resonant frequency, an expression for an upper bound of the EMP energy dissipated by the load during the first half-cycle is developed. Finally, pulser circuits to approximately simulate the half-dipole response based on this work are presented.

\section{INTRODUCTION}

A first step to determine the effects of the nuclear electromagnetic pulse (EMP) environment on electronic systems is to perform an analysis on the EMP interaction with the EM coupling mechanisms. In communications systems, the antenna is an important means of coupling EMP energy to some of the most vulnerable electronic components in the system. In this paper, the EMP interaction with the cyljndrical dipole antenna is discussed.

In classical antenna theory, the frequency-domain antenna response to a time harmonic source is found as the solution to an integral equation. ${ }^{1}$ The integral equation is normally of such complexity that numerical evaluation is required. The method of moments is one technique that has been used more recently to solve the integral equation by the formation of a matrix equation. 2 The time-domain response is then obtained by a Fourier inversion. Analytical formulas for the time-domain response are available for only very special and limiting cases. A disadvantage of a numerical solution is that the functional dependence of the response 
on the various variables. is often "lost" in the numbers. Also considerable numerical computations are required to obtain the antenna response to EMP since it has a relatively (to many sources commonly used in classical antenna theory) large frequency spectrum.

The purpose of this paper is to apply more recent treatments of the time-domain solution for the interaction of electromagnetic fields with an object for the analysis of the dipole EMP response. The singularity expansion technique formalized by Baum, ${ }^{3}$ has been used by Tesche ${ }^{4}$ and Lee and Leung to solve problems concerning cylindrical structures. This method allows the solution to be factored into an object response and the incident waveform characteristics. The object response can be split to some extent into terms associated with the geometry of the object and its electromagnetic coupling characteristics. When this technique is applied to the cylindrical dipole antenna, the time-domain response can be expressed by simple analytical formulas.

Again, it should be pointed out that the dipole antenna admittance is derived from the work performed by Lee and Leung ${ }^{5}$ which is of an approximate nature. Thus, the solutions involving the antenna admittance are necessarily approximate. However, most analysis of the EMP effects on systems require only reasonable estimates of the EMP-induced transients that couple into the system. Reasonable estimates are those estimates that permit the overall vulnerability analysis to be performed within acceptable error bounds.

In addition to theoretical analysis, this more recent work is applied to experimental techniques. In Section VII, simple pulser simulation circuits are derived from the Thevenin equivalent circuit for the half-dipole antienna.

\section{ANTENNA FUNDAMENTALS}

In considering an antenna as a receiving device, it is useful to employ Thevenin and Norton equivalent circuits to calculate the antenna response. The Thevenin and Norton equivalent circuits are shown in Figs. Ia and $1 \mathrm{~b}$ respectively. The equivalent circuit parameters are:

$\mathrm{V}$ - voltage across the load

I - current through the load 


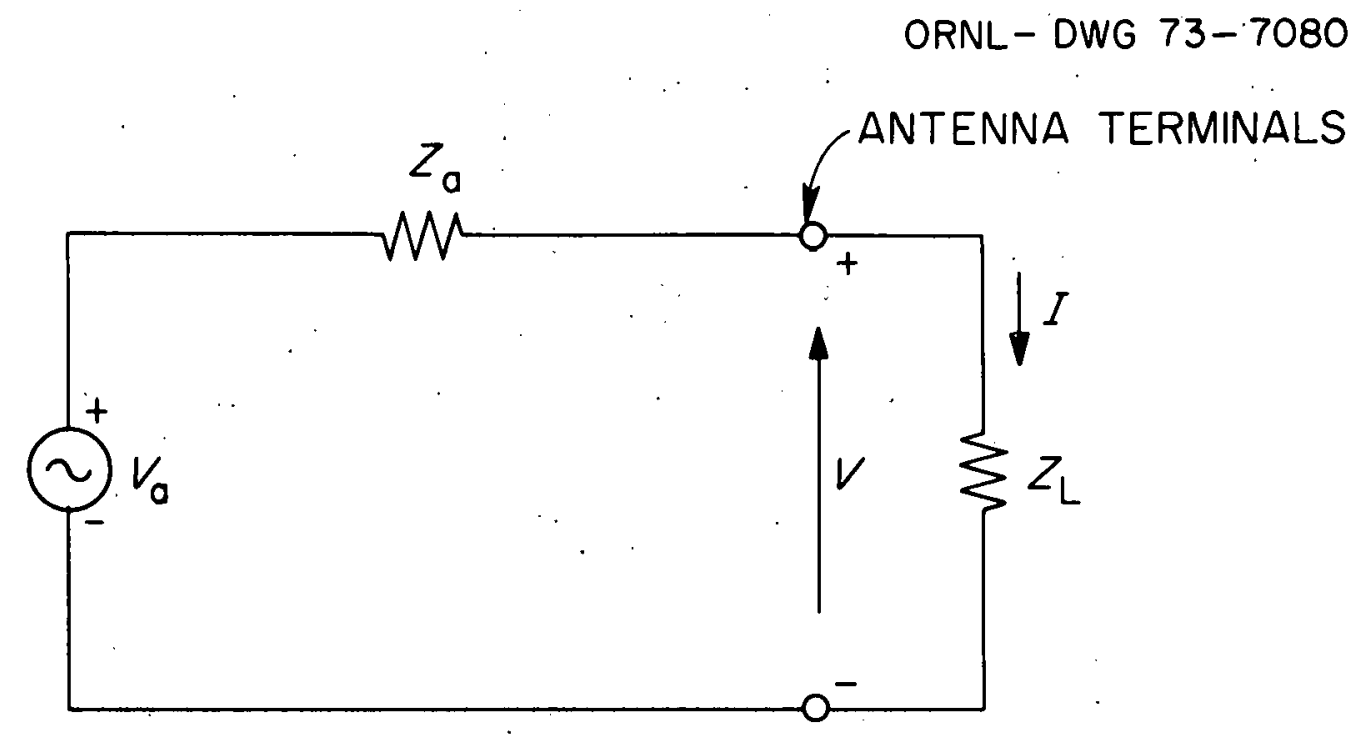

(a). THEVENIN EQUIVALENT CIRCUIT

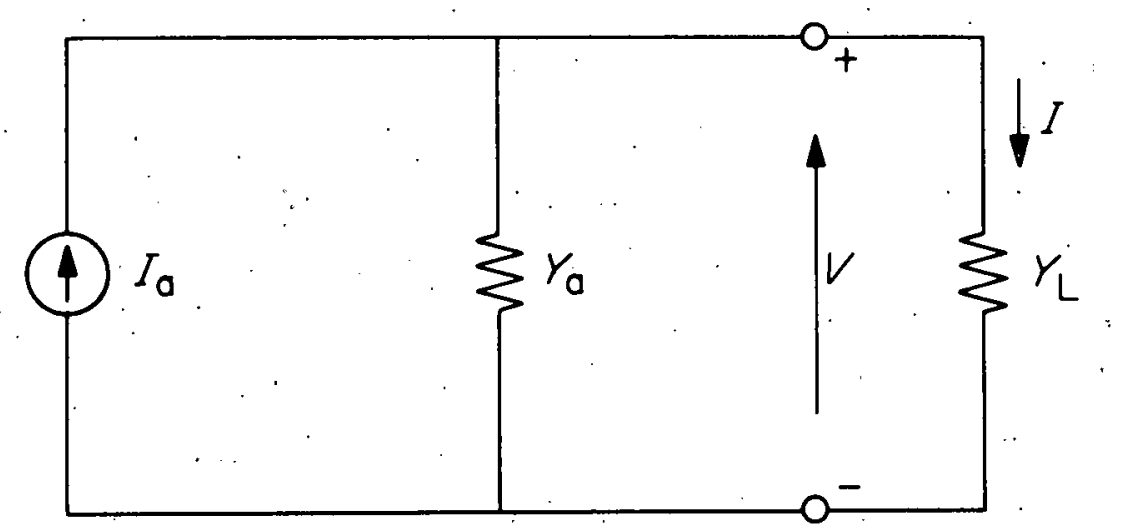

(b) NORTON EQUIVALENT CIRCUIT

Fig. 1. Equivalent Circuits for Determining Antenna Response. 
$\mathrm{Z}_{\mathrm{L}} \quad-$ load impedance

$\mathrm{Y}_{\mathrm{L}}$ - load admittance

$\mathrm{Z}_{\mathrm{a}}$ - impedance of the antenna

$\mathrm{Y}_{\mathrm{a}}$ - admittance of the antenna

$\mathrm{V}_{\mathrm{a}}$ - equivalent voltage source of the antenna and the electromagnetic environment

$I_{a}$ - equivalent current source of the antenna and the electromagnetic environment.

It is easily seen that the following circuit relationships apply:

$$
\begin{gathered}
V=\frac{V_{a}{ }^{7_{L}}}{Z_{a}+Z_{L}}=\frac{T_{a}}{Y_{a}+Y_{L}}, \\
I=\frac{I_{a} Y_{L}}{I_{a}+{ }^{I} L}=\frac{V_{a}}{Z_{a}+Z_{L}}, \\
I_{a}=Y_{a} V_{a} .
\end{gathered}
$$

The Thevenin equivalent voltage is the open-circuit voltage at the antenna's terminals, i.e., $V_{a}=V$ for $Z_{L}=\infty$. The Norton equivalent current is the short-circuit current through the antenna's terminals, i.c., $I_{a}=I$ for $\dot{Y}_{T_{l}}=\infty$. If two of the three antenna equivalent circuit, parameters $\mathrm{V}_{a}, \mathrm{I}_{a}$, and $\mathrm{Z}_{\mathrm{a}}$ are known, the electrical quantities received at the load can be calculated.

To calculate the open-circuit voltage for electric dipoles, the concept of the complex effective length, $\ell_{\text {eff }}$, of the antenna can be employed. The open-circuit voltage is defined by

$$
V_{o c}(\omega)-E_{1}(\omega) l_{\text {eff }}(\vec{k}, \omega),
$$

where $E_{1}$ is the component of the incident electric field in the direction of maximum sensitivity of the antenna. In general, the effective lengtih is a very complicated function of the radian frequency, $\omega$, antenna and ground plane geometries and the direction of the incident wave $\vec{k}$. 
For electrically small antennas such that the antenna dimensions are small compared to the radian wavelengths contained in the incident wave, the concept of equivalent length, $l_{\text {eq }}$, can be used. The equivalent length is only a function of the antenna and ground plane geometries and is related to the effective length by

$$
\ell_{\text {eff }} \sim \ell_{\text {eq }} \text { for } \omega_{0}>\omega \rightarrow 0
$$

where $\omega_{0}$ is the first resonant radian frequency of the antenna.

\section{THE SHORT-CIRCUIT CURRENT}

In practice, the symmetric cylindrical electric dipole consists of two highly conducting circular cylindrical tubes or rods each with radius $a$, and both aligned along a common axis with half-length $l$ as shown in Fig. 2a. The half-dipole antenna* generally consists of a highly conducting circular cylindrical tube or rod with radius a and length $l$, erected perpendicular to a highly conducting ground plane. The halfdipole with its image is shown in Fig. $2 b$.

- Short circuiting the electric dipole shown in Fig. 2 a gives the ... cylindrical thin-wire $(l \gg a)$ scatterer shown in Fig. 2c. The thin-wire scatterer is a perfectly conducting circular cylinder with a half length $l$ and a radius a. The incident plane wave pulse is also shown in Fig. $2 c$ and is polarized with the magnetic field perpendicular to the cylinder and the angle of incidence is $\theta$, measured from the axis of the cylinder. The short-circuit current for the symmetric dipole is the total current at $\mathrm{z}=0$.

The solution of electromagnetic interaction problems by the singularity expansion method as formalized by $\mathrm{Baum}^{3}$ permits the direct calculation of the time-domain response of the electromagnetic quantity by considering the singularity points, e.g., the natural frequencies, associated with the frequency-domain solution. Recently, Tesche applied this singularity expansion technique to the thin-wire scatterer.4

\footnotetext{
${ }^{*}$ The half-dipole is also called a whip or monopole antenna.
} 


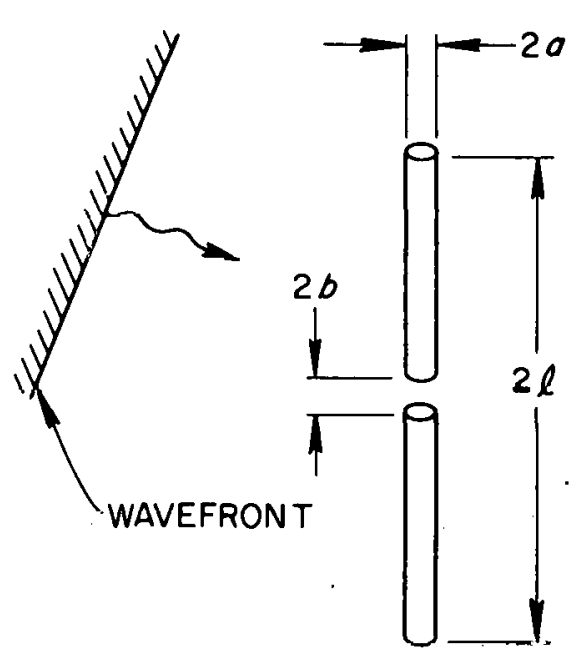

(a) THE DIPOLE

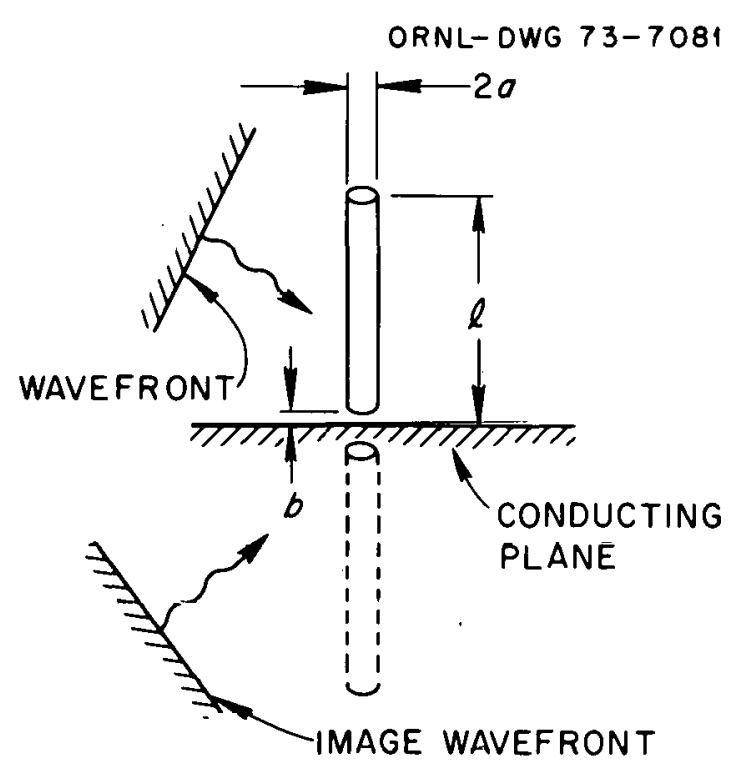

(b) THE HALF-DIPOLE

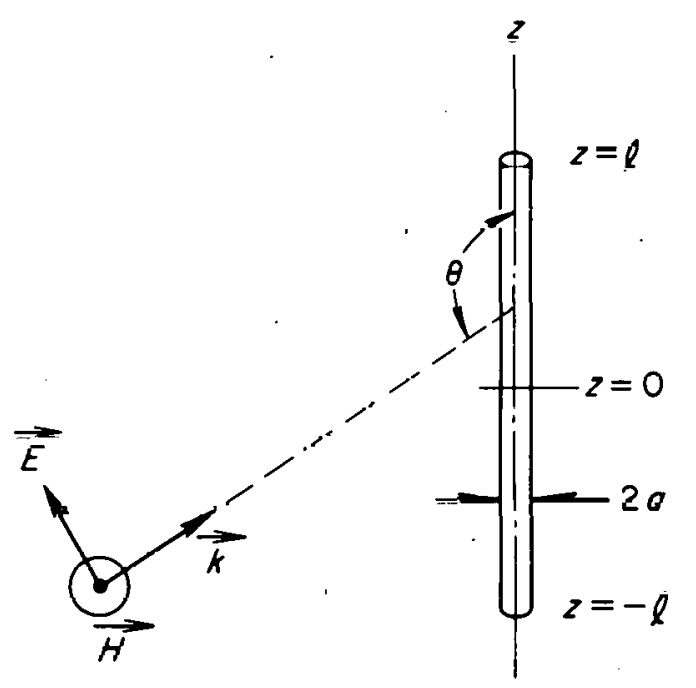

(c) THE INCIDENT FIELD AND THIN CYLINDRICAL SCATTERER-A SHORT-CIRCUITED DIPOLE ANTENNA

Fig. 2. Cylindrical Dipole Antennas. 
The total axial current at $z$ on a thin-wire scatterer for $l>a$ is given $b^{7}$

$$
\left.i(z, t)=4 \cdot E_{o} \& \quad \operatorname{Real}\left[\sum_{m=1}^{M} M_{m}(z) C_{m}(\theta) \frac{e^{s_{m} t}}{\left(2 s_{m} \ell / c\right.}\right)\right],
$$

where the time history of the incident field $E(t)$ is a step function of time, i.e., $E(t)=E_{0} U(t)$ where $U(t)$ is the unit step function, and $M$ is the number of poles used in the calculation. $\mathrm{M}_{\mathrm{m}}(\mathrm{z})$ is the $\mathrm{m}^{\text {th }}$ normilized natural mode, $C_{m}(\theta)$ is the $m^{\text {th }}$ coupling coefficient, and $s_{m}$ is the $m^{\text {th }}$ natural frequency.

Equation (3.1) can be written as

$$
i(z, t)=4 \mathrm{E}_{0} \ell \sum_{m=1}^{M} e^{-\gamma \dot{m} t}\left[A_{m}(z, \theta) \cos \omega_{m} t+B_{m}(z, \theta) \sin \omega_{m} t\right],(3.2)
$$

where $s_{m}=-\gamma_{m}+j \omega_{m}, \gamma_{m}$ is the natural damping constant and $\omega_{m}$ is the natural resonant. frequency and

$$
\begin{aligned}
& A_{m}=\operatorname{Re}\left[\frac{M_{m}(z) C_{m}(\theta)}{2 s_{m} \cdot l / c}\right] . \\
& B_{m}=\operatorname{Im}\left[\frac{M_{m}(z) C_{m}(\theta)}{2 s_{m} \cdot l / c}\right],
\end{aligned}
$$

where $\operatorname{Re}(\mathrm{z})$ and $\operatorname{Im}(\mathrm{z})$ are the real and imaginary parts of $\mathrm{z}$ respectively.

Tesche found that for late times, i.e., $t>6 \mathrm{l} / \mathrm{c}$, the current can be accurately conputed with three poles $(\mathrm{M}=3)$. The complete time response can be accurately described with ten poles.4 A good approximation of the current can be obtained with five poles as seen from Fig. 14 in Reference 4.

Table $I$ gives the values of $\gamma_{m}, B_{m}, A_{m}(z, \theta)$ and $B_{m}(z, \theta)$ up to $m \cdot=10$ for $\ell / a=100.0, z=0$ and $\ell / 2$; and $\theta=\pi / \tau, \pi / 3$. Table 2 gives the values of the natural quantities for a wide range of $\Omega=\ln (2 l / a)$ at $\dot{z}=0$. 
Table 1. The Natural Resonant Frequeneies, Damping Constants, and Coefficients Am and $\mathrm{Bm}$ for $l / a=100$

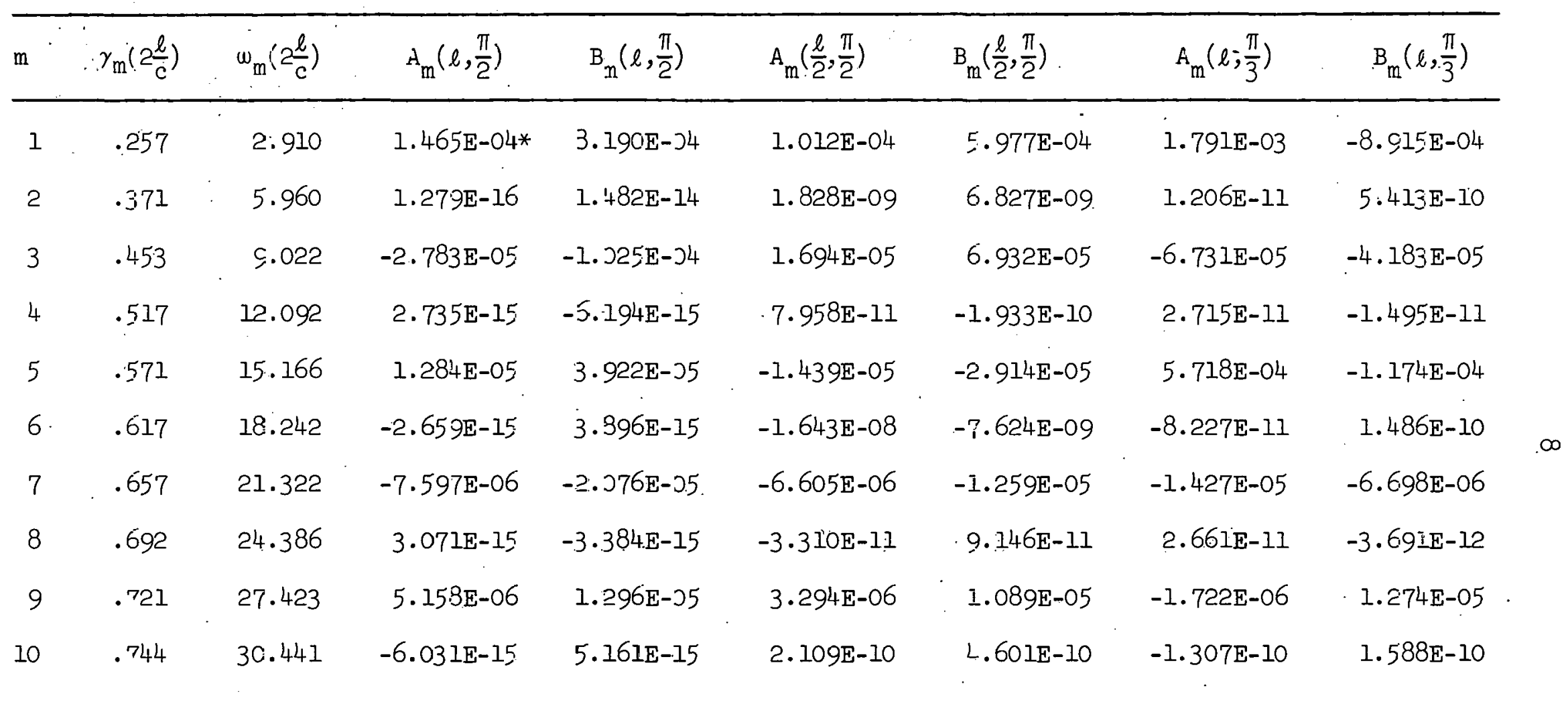

${ }^{*} 1.465 \mathrm{E}-04=1.465 \times 10^{-4}$. 
Table.2. The Natural Resonance Frequencies, Damping Constants, and Coefficients $A_{m}$ and $B_{m}$ for $\theta=\pi / 2$ and $z=l$

\begin{tabular}{|c|c|c|c|c|c|c|c|c|}
\hline \multirow[t]{2}{*}{$\mathrm{m}$} & \multicolumn{2}{|c|}{$\gamma_{m}(2 \ell / c)$} & \multicolumn{2}{|c|}{$\omega_{m}(2 \ell / c)$} & \multicolumn{2}{|c|}{$\mathrm{A}_{\mathrm{m}}$} & \multicolumn{2}{|c|}{$\overline{B_{m}}$} \\
\hline & $\Omega=8$ & $\Omega=9$ & $\dot{\Omega}=8$ & $\Omega=9$ & $\Omega=8$ & $\Omega=9$ & $\Omega=8$ & $\Omega=9$ \\
\hline 1 & .334 & .302 & 2.776 & 2.840 & $2.8249 \mathrm{E}-04$ & $2.1650 \mathrm{E}-04$ & I. $13.86 \mathrm{E}-03$ & $9.9551 \mathrm{E}-0.4$ \\
\hline 2 & .496 & .444 & 5.748 & 5.851 & $2.1805 \mathrm{E}-14$ & $9.6909 \mathrm{E}-15$ & $3.0366 \mathrm{E}-14$ & $2.3264 \mathrm{E}-14$ \\
\hline 3 & .603 & .544 & 8.738 & 8.877 & $-5 \cdot 345+\mathrm{E}-\mathrm{O}$ & $4.2013 \mathrm{E}-05$ & $-1.3838 \mathrm{E}-04$ & $-1.2372 \mathrm{E}-04$ \\
\hline 4 & .684 & .619 & 11.734 & 11.914 & $-2.2833 \mathrm{E}-15$ & $1.0572 \mathrm{E}-16$ & $-1.3072 \mathrm{E}-14$ & $-9.2419 E-15$ \\
\hline 5 & .744 & .680 & 14.696 & 14.956 & $-2.3315 \mathrm{E}-05$ & $1.8737 \mathrm{E}-05$ & $5.1536 \mathrm{E}-05$ & $4.6354 \mathrm{E}-05$ \\
\hline 6 & -- & .731 & -- & $17 \cdot 995$ & -- & $-2.0889 \mathrm{E}-15$ & -- & $6.1771 \mathrm{E}-15$ \\
\hline 7 & -- & .773 & -- & 21.036 & -- & $-1.0807 \mathrm{E}-05$ & -- & $-2.4142 E-05$ \\
\hline 8 & -- & .811 & -- & 24.061 & -- & $2.5395 \mathrm{E}-15$ & -- & $-4.6827 E-15$ \\
\hline 9 & -- & .848 & -- & .27 .073 & -- & $7.2924 \mathrm{E}-06$ & -- & $1.4948 \mathrm{E}-05$ \\
\hline \multirow[t]{2}{*}{10} & -- & .879 & -- & 30.070 & -- & $-5.8109 \mathrm{E}-15$ & -- & $7.1880 \mathrm{E}-15$ \\
\hline & $\Omega=10$ & $\Omega=11$ & $\Omega=10$ & $\Omega=11$ & $\Omega=10$ & $\Omega=11$ & $\Omega=10$ & $\Omega=11$ \\
\hline 1 & .273 & .247 & 2.887 & $\cdot 2.923$ & $1.6855 \mathrm{E}-04$ & $1.3387 \mathrm{E}-04$ & $8.7835 \mathrm{E}-04$ & $7.8316 \mathrm{E}-04$ \\
\hline 2 & .397 & .356 & 5.926 & 5.980 & $2.6789 \mathrm{E}-15$ & $-1.1251 \mathrm{E}-15$ & $1.7527 \mathrm{E}-14$ & $1.3267 \mathrm{E}-14$ \\
\hline 3 & .485 & .433 & 8.977 & 9.049 & $-3.2590 \mathrm{E}-05$ & $-2.5407 \mathrm{E}-05$ & $-1.0992 \mathrm{E}-04$ & $-9.7774 \mathrm{E}-05$ \\
\hline 4 & .555 & .494 & 12.036 & 12.124 & $2.0333 E-15$ & $3.0601 \mathrm{E}-15$ & $-7.2460 \mathrm{E}-15$ & $-5.5635 \mathrm{E}-15$ \\
\hline 5 & .612 & .545 & 15.100 & 15.203 & $1.4872 \mathrm{E}-05$ & $1.1643 \mathrm{E}-05$ & $4.1858 \mathrm{E}-05$ & $3.7496 \mathrm{E}=0.05$ \\
\hline 6 & $.660^{\circ}$ & .589 & 18.168 & 18.285 & $-2.3841 E-15$ & $-2.7841 E-15$ & $4.4979 E-15$ & $3.5199 \mathrm{E}-15$ \\
\hline 7 & .702 & .628 & 21.238 & 21.369 & $-8.7125 \mathrm{E}-06$ & $-6.9034 E-06$ & $-2.2030 \mathrm{E}-05$ & $-1.9918 \mathrm{E}-05$ \\
\hline
\end{tabular}


Table 2. (Cont'd)

\begin{tabular}{|c|c|c|c|c|c|c|c|c|}
\hline \multirow[t]{2}{*}{$\mathrm{m}$} & \multicolumn{2}{|c|}{$\gamma_{\mathrm{m}}(2 \ell / c)$} & \multicolumn{2}{|c|}{$w_{m}(2 \ell / c)$} & \multicolumn{2}{|c|}{$\mathrm{A}_{\mathrm{m}}$} & \multicolumn{2}{|c|}{$\mathrm{B}_{\mathrm{m}}$} \\
\hline & $\Omega=10$ & $\Omega=11$ & $\Omega=10$ & $\Omega=11$ & $\Omega=10$ & $\Omega=11$ & $\Omega=10$ & $\Omega=11$ \\
\hline 8 & .739 & .651 & 24.295 & $24.43 \varepsilon$ & c. $9435 E-15$ & $3.1116 \mathrm{E}-15$ & $-3.8717 \mathrm{E}-15$ & $-3.0701 \mathrm{E}-15$ \\
\hline 9 & .770 & .638 & $27 \cdot 325$ & $27.47 \mathrm{~d}$ & $5.9229 \mathrm{E}-06$ & $4.6795 \mathrm{E}-06$ & $1.3726 \mathrm{E}-05$ & $1.2441 \mathrm{E}-05$ \\
\hline \multirow[t]{2}{*}{10} & .796 & .709 & 30.337 & 30.500 & $-6.0441 \mathrm{E}-15$ & $-5.9564 \mathrm{E}-15$ & $5.9213 \mathrm{E}-15$ & $4.674 \mathrm{IE}-15$ \\
\hline & $\Omega=12$ & $\Omega=12.5$ & $\Omega=12$ & $\Omega=12.5$ & $\Omega=12$ & $\Omega=12.5$ & $\Omega=12$ & $\Omega=12.5$ \\
\hline 1 & .226 & .216 & 2.950 & 2.961 & $1.0845 \mathrm{E}-04$ & $1.0845 \mathrm{E}-04$ & $9.8272 \mathrm{E}-05$ & $6.7165 \mathrm{E}-04$ \\
\hline 2 & $\cdot 321$ & .306 & 6.020 & 6.035 & $-3 \cdot 1272 E-15$ & $-3 \cdot 7262 \mathrm{E}-15$ & $1.0194 \mathrm{E}-14$ & $8.9968 \mathrm{E}-15$ \\
\hline 3 & .388 & .369 & 9.101 & 9.122 & $-2.0118 \mathrm{E}-05$ & $-1.8026 \mathrm{E}-05$ & $-8.7517 \mathrm{E}-05$ & $-8.3044 E-05$ \\
\hline 4 & .441 & .418 & 12.188 & 12.213 & $3.4948 \mathrm{E}-15$ & $3.5776 \mathrm{E}-\mathrm{I} 5$ & $-4.2744 \mathrm{E}-15$ & $-3.7631 \mathrm{E}-15$ \\
\hline 5 & .486 & .460 & 15.278 & $15.3 \mathrm{i} 7$ & $9.1505 \mathrm{E}-06$ & $8.1536 \mathrm{E}-06$ & $3.3576 \mathrm{E}-05$ & $3.1825 \mathrm{E}-05$ \\
\hline 5 & .525 & .496 & 18.370 & 18.403 & $-2.9068 \mathrm{E}-15$ & $-2.8987 \mathrm{E}-15$ & $2.7194 \mathrm{E}-15$ & $2.3932 \mathrm{E}-15$ \\
\hline 7 & .560 & .529 & 21.463 & 21.500 & $-5.4281 \mathrm{E}-06$ & $-4.8241 \mathrm{E}-06$ & $-1.7897 \mathrm{E}-05$ & $-1.6966 \mathrm{E}-05$ \\
\hline 3 & $\cdot 588$ & .555 & 24.541 & $24 \cdot 530$ & $3.0870 \mathrm{E}-15$ & $3.0276 \mathrm{E}-15$ & $-2.3847 E-15$ & $-2.0996 \mathrm{E}-15$ \\
\hline 9 & .610 & .575 & 27.587 & 27.630 & $3.6577 \mathrm{E}-06$ & $3.2392 \mathrm{E}-06$ & 1. $1182 \mathrm{E}-05$ & $1.0594 \mathrm{E}-0.5$ \\
\hline \multirow[t]{2}{*}{10} & .628 & .591 & 30.615 & 30.650 & $-5.6648 E-15$ & $-5.4684 E-15$ & $3.6169 \mathrm{E}-15$ & $3.1799 \mathrm{E}-15$ \\
\hline & $\Omega=13$ & $\Omega=13.5$ & $\Omega=13$ & $\Omega=13.5$ & $\Omega=13$ & $\Omega=13.5$ & $\Omega=13$ & $\Omega=13.5$ \\
\hline 1 & .207 & .199 & 2.971 & 2.930 & $8.9423 \mathrm{E}-05$ & $8.1687 \mathrm{E}-05$ & $6.4091 \mathrm{E}-04$ & $6.1276 \mathrm{E}-04$ \\
\hline 2 & .292 & .279 & 6.1050 & 6.052 & $-4.1486 E-15$ & $-4.4403 E-15$ & $7 \cdot 9767 \mathrm{E}-15$ & $7.1044 \mathrm{E}-15$ \\
\hline 3 & .351 & .335 & 9.140 & 9.156 & $-1.6227 \mathrm{E}-05$ & $-1.4673 E-05$ & $-7.8960 \mathrm{E}-05$ & $-7.522 .6 \mathrm{E}-05$ \\
\hline+ & .397 & .378 & 12.234 & 12.253 & $3.604 \mathrm{OE}-15$ & $3 \cdot 5909 \mathrm{E}-15$ & $-3 \cdot 3260 E-15$ & $-2.9523 E-15$ \\
\hline
\end{tabular}


Table 2 (Cont'd)

\begin{tabular}{|c|c|c|c|c|c|c|c|c|}
\hline \multirow[t]{2}{*}{$\mathrm{m}$} & \multicolumn{2}{|c|}{$\gamma_{\mathrm{m}}(2 \ell / \mathrm{c})$} & \multicolumn{2}{|c|}{$\omega_{m}(2 \ell / c)$} & \multicolumn{2}{|c|}{$A_{m}$} & \multicolumn{2}{|c|}{$\mathrm{B}_{\mathrm{m}}$} \\
\hline & $\Omega=13$ & $\Omega=13.5$ & $\Omega=13$ & $\Omega=13.5$ & $\Omega=13$ & $\Omega=13.5$ & $\Omega=13$ & $\Omega=13.5$ \\
\hline 5 & .436 & .415 & $15 \cdot 332$ & 15.353 & $7.2965 \mathrm{E}-06$ & $6.5582 \mathrm{E}-06$ & $3.0215 \mathrm{E}-05$ & $2.8736 \mathrm{E}-05$ \\
\hline 6 & .470 & .446 & 18.431 & 18.455 & $-2.8618 E-15$ & $-2.8060 E-15$ & $2.1122 \mathrm{E}-15$ & $1.8711 \mathrm{E}-15$ \\
\hline 7 & .500 & .474 & 21.532 & 21.558 & $-4 \cdot 3019 E-06$ & $-3.8514 \mathrm{E}-06$ & $-1.6099 \mathrm{E}-05$ & $-1.5297 \mathrm{E}-05$ \\
\hline 8 & .525 & .497 & 24.614 & 24.643 & $2.9497 \mathrm{E}-15$ & $2.8609 \mathrm{E}-15$ & $-1.8522 \mathrm{E}-15$ & $-1.6392 \mathrm{E}-15$ \\
\hline 9 & .543 & .514 & 27.665 & 27.696 & $2.8776 \mathrm{E}-06$ & $2.5667 \mathrm{E}-06$ & $1.0045 \mathrm{E}-05$ & $9.5361 \mathrm{E}-06$ \\
\hline \multirow[t]{2}{*}{10} & .558 & .527 & 30.697 & 30.729 & $-5.2595 E-15$ & $-5.0473 \mathrm{E}-15$ & $2.8021 \mathrm{E}-15$ & $2.4780 \mathrm{E}-15$ \\
\hline & $\Omega=14$ & $\Omega=14.5$ & $\Omega=14$ & $\Omega=14.5$ & $\Omega=14$ & $\Omega=14.5$ & $\Omega=14$ & $\Omega=14.5$ \\
\hline 1 & .192 & .135 & 2.983 & 2.995 & $7.4890 \mathrm{E}-05$ & $6.8891 \mathrm{E}-05$ & $5.8690 \mathrm{E}-0.4$ & $5.6308 \mathrm{E}-05$ \\
\hline 2 & .267 & .256 & 6.073 & 6.083 & $-4.6349 E-15$ & $-4 \cdot 7572 \mathrm{E}-15$ & $6.355 ? \mathrm{E}-15$ & $5.7087 \mathrm{E}-15$ \\
\hline 3 & .320 & .306 & 9.163 & 9.182 & $-1.3324 \mathrm{E}-05$ & $-1.2147 \mathrm{E}-05$ & $-7.1805 \mathrm{E}-05$ & $-6.8664 \mathrm{E}-05$ \\
\hline 4 & .361 & .344 & 12.270 & 12.284 & $3.5510 \mathrm{E}-15$ & $3.4931 \mathrm{E}-15$ & $-2.6320 \mathrm{E}-15$ & $-2.3565 \mathrm{E}-15$ \\
\hline 5 & .395 & .376 & $15 \cdot 37 ?$ & $15 \cdot 389$ & $5 \cdot 9206 \mathrm{E}-06$ & $5.3677 \mathrm{E}-06$ & $2.7379 \mathrm{E}-05$ & $2.6133 \mathrm{E}-05$ \\
\hline 6 & $.42+$ & .404 & 18.475 & 18.495 & $-2.7383 E-15$ & $-2.6637 \mathrm{E}-15$ & $1.6644 \mathrm{E}-15$ & $1.4867 \mathrm{E}-15$ \\
\hline 7 & .450 & .429 & $21.58 \geq$ & 21.602 & $-3.4627 \mathrm{E}-06$ & $-3.1267 \mathrm{E}-06$ & $-1.4559 \mathrm{E}-05$ & $-1.3879 \mathrm{E}-05$ \\
\hline 8 & .472 & .449 & 24.663 & 24.690 & $2.7667 \mathrm{E}-15$ & $2.6708 \mathrm{E}-15$ & $-1.4562 E-15$ & $-1.2992 \mathrm{E}-15$ \\
\hline 9 & .487 & .463 & $27 \cdot 72 ?$ & $27 \cdot 745$ & $2.2994 \mathrm{E}-06$ & $2.0692 \mathrm{E}-06$ & $9.0665 \mathrm{E}-06$ & $3.6343 \mathrm{E}-06$ \\
\hline 10 & .499 & .474 & 30.757 & 30.780 & $-4.8382 \mathrm{E}-15$ & $-4.6360 \mathrm{E}-15$ & $2.2004 \mathrm{E}-15$ & $1.9626 \mathrm{E}-15$ \\
\hline
\end{tabular}


Table 2. (Ccnt'd)

\begin{tabular}{|c|c|c|c|c|c|c|c|c|}
\hline \multirow[t]{2}{*}{$\mathrm{m}$} & \multicolumn{2}{|c|}{$\gamma_{\mathrm{m}}(2 \mathrm{l} / \mathrm{c})$} & \multicolumn{2}{|c|}{$u_{m}(2 \ell / c)$} & \multicolumn{2}{|c|}{$A_{m}$} & \multicolumn{2}{|l|}{$\mathrm{B}_{\mathrm{m}}$} \\
\hline & $\Omega=15$ & $\Omega=15 \cdot 5$ & $\Omega=15$ & $\Omega=15 \cdot 5$ & $\Omega=15$ & $\cdot \Omega=15 \cdot 5$ & $\Omega=15$. & $\Omega=15.5$ \\
\hline 1 & .178 & .172 & 3.302 & 3.008 & $6.3571 \mathrm{E}-05$ & $5.8833 \mathrm{E}-05$ & $5.4106 \mathrm{E}-04$ & $5.2065 \mathrm{E}-04$ \\
\hline$\geq$ & .246 & .237 & 6.392 & 6.100 & $-4.8254 E-15$ & $-4.8532 \mathrm{E}-15$ & $5.1485 \mathrm{E}-15$ & $4.6608 \mathrm{E}-15$ \\
\hline 3 & .293 & .281 & 9.192 & 9.202 & $-1.1115 \mathrm{E}-05$ & $-1.0207 \mathrm{E}-05$ & $-6.5773 E-05$ & $-6 \cdot 3104 \mathrm{E}-05$ \\
\hline 4 & .330 & .316 & 12.297 & 12.308 & $3.4234 \mathrm{E}-15$ & $3 \cdot 3465 \mathrm{E}-15$ & $-2.1187 \mathrm{E}-15$ & $-1.9125 \mathrm{E}-15$ \\
\hline 5 & .360 & .345 & $15 \cdot+03$ & 15.416 & $4.8862 \mathrm{E}-06$ & $4.4648 \mathrm{E}-i 5$ & $2.4987 \mathrm{E}-05$ & $2.3931 \mathrm{E}-05$ \\
\hline 5 & .385 & .369 & 18.511 & 18.525 & $-2.5859 \mathrm{E}-15$ & $-2.5070 \mathrm{E}--5$ & $1.3337 \mathrm{E}-15$ & $1.2013 \mathrm{E}-15$ \\
\hline 7 & .409 & $\cdot 391$ & 21.519 & 21.635 & $-2.8351 \mathrm{E}-06$ & $-2.5810 E=06$ & $-1.3254 \mathrm{E}-05$ & $-1.2678 E-0.5$ \\
\hline 3 & .427 & .408 & 24.709 & 24.725 & $2 \cdot 5756 \mathrm{E}-15$ & $2.4828 \mathrm{E}-15$ & $-1.1640 \mathrm{E}-15$ & $-1.0473 E-15$ \\
\hline 9 & .441 & .420 & $27 \cdot 765$ & 27.782 & $1.8703 \mathrm{E}-06$ & $1.6976 \mathrm{E}-06$ & $8.2366 \mathrm{E}-06$ & $7.8706 \mathrm{E}-\mathrm{c} 6$ \\
\hline 10) & .451 & .430 & 30.301 & 30.819 & $-4 \cdot 4428 E-15$ & $-4.2597 \mathrm{E}-.15$ & $1.7583 \mathrm{E}-15$ & $1.5822 \mathrm{E}-15$ \\
\hline
\end{tabular}


The Laplace transform of Eq. (3.2) in terms of the Laplace transform variable $\mathrm{s}$ is

$$
I(z, s)=4 E_{o} l \sum_{m=1}^{M} \frac{A_{m}(z, \theta)\left(s+\gamma_{m}\right)+B_{m}(z, \theta) w_{m}}{\left(s+\gamma_{m}\right)^{2}+\omega_{m}^{2}} .
$$

For EMP analysis of communications antennas, the most interesting and common case to consider is the symmetrical dipole or half-dipole, i.e., $z=0$, with the angle of incidence $\theta=\pi / 2$.

Equation (3.5) is the short-circuit current response of a dipole antenna subjected to an incident field with an angle of incidence $\theta$ and with a step-function time history. The current at $z=0$ for an incident field with $\theta=\pi / 2$ and a time history $e^{-\alpha t}$ is given by

$$
I_{\alpha}=4 E_{0} \ell \sum_{m=1}^{M}\left[\frac{s}{s+\alpha}\right]\left\lfloor\frac{A_{m}\left(s+\gamma_{m}\right)+B_{m} w_{m}}{\left(s+\gamma_{m}\right)^{2}+w_{m}^{2}}\right\rfloor .
$$

The inverse Laplace transform of Eq. (3.6) is

$$
\begin{aligned}
i_{\alpha}= & 4 E_{o} \ell \sum_{m=1}^{M}\left\{D_{m} e^{-\alpha t}+e^{-\gamma_{m} t}\left[\left(A_{m}-D_{m}\right) \cos \omega_{m} t+\right.\right. \\
& \left.\left.\frac{A_{m} \gamma_{m}+B_{m} \beta_{m}-A_{m}\left(\alpha+\gamma_{m}\right)+\left(\alpha-\gamma_{m}\right) D_{m}}{\omega_{m}} \sin \omega_{m} t\right]\right\} ;,
\end{aligned}
$$

where

$$
D_{m}=\frac{A_{m} \alpha^{2}-\left(A_{m} \gamma_{m}+B_{m} \omega_{m}\right) \alpha}{\left(\alpha-\gamma_{m}\right)^{2}+\omega_{m}^{2}}
$$

For the doubie exponential incident EMP, $E(t)=E_{0}\left(e^{-\alpha t}-e^{-\eta t}\right)$, the current can be calculated by

$$
i=i_{\alpha}-i_{\eta},
$$

where $i_{\eta}$ is given by $E_{-1} \cdot(3.7)$ with ox replased by ${ }^{\prime}{ }_{n}$ 
The substitution of $\alpha$ and $\eta$ into Eq. (3.7) as. indicated by Eq. (3.9) gives the time domain short-circuit current response of the electric dipole antenna to a double exponential incident wave as

$$
\begin{aligned}
i= & 4 \mathrm{E}_{0} l \sum_{m=1}^{M}\left\{D_{m \alpha} e^{-\alpha t}-D_{m \eta} e^{-\eta t}+e^{-\gamma_{m} t}\left[\left(D_{m \eta}-D_{m \alpha}\right) \cos \omega_{m} t+\right.\right. \\
& \left.\left.\frac{A_{m}(\eta-\alpha)+\left(\alpha-\gamma_{m}\right) D_{m \alpha}-\left(\eta-\gamma_{m}\right) D_{m \eta}}{u m} \sin \omega_{m} t\right]\right\},
\end{aligned}
$$

where $D_{m \eta}$ is given by Eq. (3.8) with $\alpha$ replaced by $\eta$.

For many EMP applications $\eta$ is on the order of $2 \times 10^{8}$ and $\alpha$ is several orders of magnitude smaller than $\eta$ such that $\eta \gg \alpha$. Also from Tables 1 and 2 , the relations $\omega_{m} \gg \gamma_{m}$ and $B_{m}>A_{m}$ are evident. For VHF and UHF antennas, $\omega_{m} \gg \alpha$ and $D_{m \alpha}$ can be approximated by

$$
\mathrm{D}_{\mathrm{mr}:} \approx \frac{-\mathrm{B}_{\mathrm{m}} \alpha}{\omega \mathrm{w}_{\mathrm{m}}}
$$

and

$$
D_{m \eta} \approx \frac{A_{m} \eta^{2}-B_{m} \omega_{m} \eta}{\left(\eta-\gamma_{m}\right)^{2}+\omega_{m}^{2}}
$$

ALso, f'or thin dipole VHF and UHF antennas (20 MHz to $500 \mathrm{MHz}$ ) with $\eta \gg \alpha$, it can be shown that $\left|\left(\alpha-\gamma_{m}\right) D_{m \alpha}\right| \ll\left|\left(\eta-\gamma_{m}\right) D_{m \eta}\right|$. The current response can be written to a good approximation as

$$
\begin{aligned}
i= & 4 E_{o} l \sum_{m=1}^{M}\left\{D_{m \alpha} e^{-\alpha t}-D_{m \eta} e^{-\eta t}+e^{-\gamma_{m} t}\right. \\
& {\left.\left[\left(D_{m \eta}-D_{m \alpha}\right) \cos \omega_{m} t+\frac{\eta A_{m}-\left(\eta-\gamma_{m}\right) D_{m \eta}}{\omega_{m}} \text { sin } \omega_{m} t\right]\right\} . }
\end{aligned}
$$

where $D_{m \alpha}$ and $D_{m \eta}$ are calculated from Eqs. (3.11) and (3.12).respectively. 


\section{THE DIPOLE ADMITTANCE}

Due to the complicated geometry of the cylindrical dipole antenna and the feed line, analytically accurate formulas for the antenna admittance are generally not available. There are, however, low and high frequency approximations for the admittance, and there are "rule of thumb" techniques to account for the effects of the feedline.

In most investigations of the cylindrical dipole admittance, the antenna is considered as a thin cylindrical structure excited by an idealized infinitesimal gap voltage source. The finite voltage maintained across the infinitesimal gap corresponds to an infinite slice capacitance at the antenna's terminals. The singularity due to the infinite susceptance of the slice capacitance is normally removed by calculating the antenna current at a distance $b$ away from the feed corresponding to the half-width of a finite gap. This procedure of "subtractingout" the singularity is questionable theoretically and necessarily approximate. However, this procedure does give results that are in reasonable agreement with experimental results. Nevertheless, the possibility of large errors in the susceptance does exist and this should be investigated further for transient problems.

The implication of the infinitesimal-gap solution with the singularity removed is not clear cut for transient problems. Presumably, we can still use it. Physically, it means that we have ignored the effect due to a base (feedpoint) capacitance providing, of course, that the base capacitance is indeed subtracted from the solution. ${ }^{8}$

The dominant resonant currents on a thin dipole antenna excited by an infinitesimal-gap voltage source have been investigated by Lee and Leung. ${ }^{5}$ The geometry of a thin cylinder with an infinitesimal-gap excitation at its center is shown in Fig. 3a. The late-time current due to a voltage source with a unit step-function time history is approximately given by

$$
\begin{gathered}
i(z, t) \sim \sum_{n=-N}^{N}\left[\frac{j}{30 n \pi} \frac{\cos \left(\frac{n \pi z}{2 l}\right)}{\ln \left(4 \dot{l}|z| / \pi^{2} a^{2} n \pi\right)} e^{\left.-j W_{n} t\right]}+\right. \\
\frac{|z|-l}{60 \operatorname{ct}\left[\ln \left(\frac{\cot \pi}{\Gamma a^{2}}\right)\right]^{2}},
\end{gathered}
$$




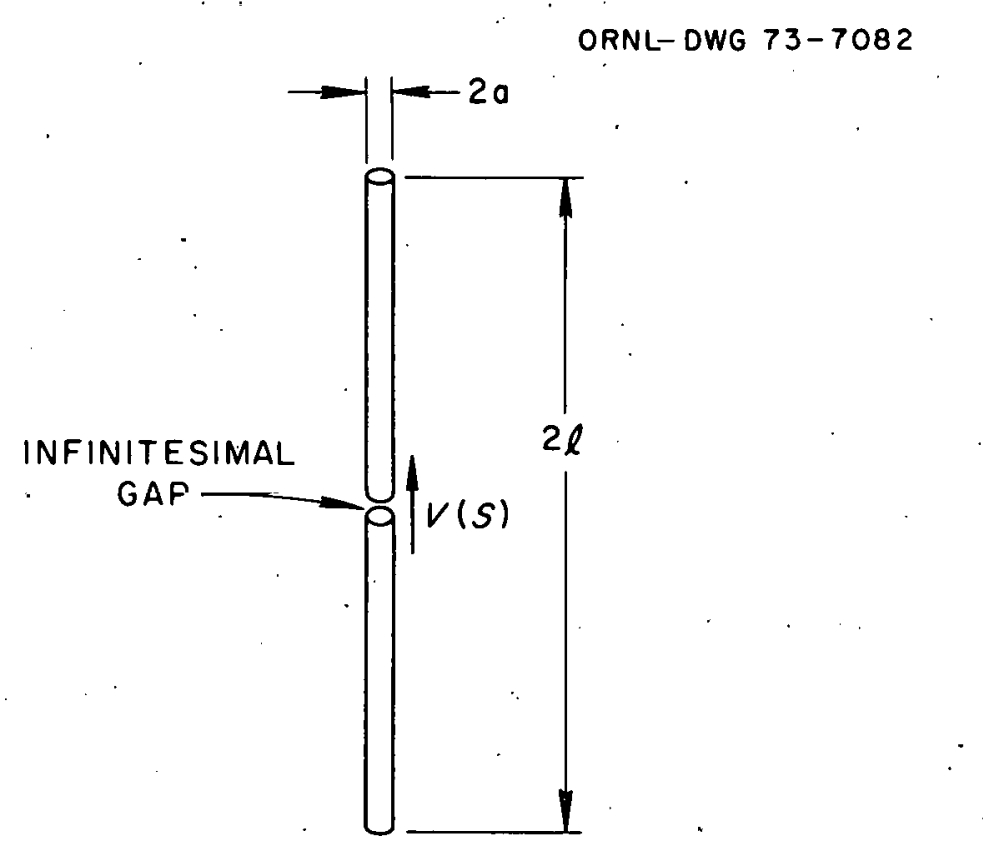

(a) CYLINDRICAL DIPOLE WITH A DELTA-GAP VOLTAGE SOURCE

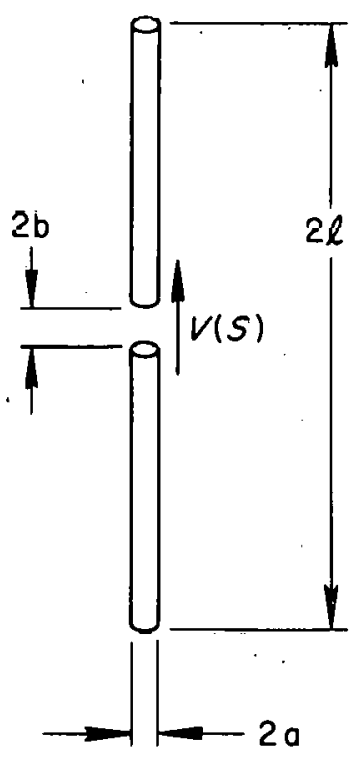

(b) CYLINDRICAL DIPOLE WITH A FINITE-GAP VOLTAGE SOURCE

Fig. 3. The Cylindrical Dipole Antenna. 
where only odd values of $\mathrm{n}$ are used, $\mathrm{N}$. is a real constant chosen such that $\mathrm{N} \ll \ell / \mathrm{a},{ }^{*} \Gamma=1.78107, \mathrm{c}$ is the free space speed of light and

$$
\mathrm{W}_{\mathrm{n}}=\frac{\mathrm{n} \pi \mathrm{c}}{2 l}\left[1+\frac{1+j \frac{2}{\pi} \ln (2 \mathrm{n} \pi)}{4 \mathrm{n} \ln \left(\Gamma \frac{\mathrm{a} \cdot \mathrm{n} \mid \pi}{2 l}\right)}\right]
$$

The real and imaginary parts of $W_{n}$ can be written as

$$
\begin{aligned}
\operatorname{Re} \cdot \mathrm{W}_{\mathrm{n}} & =\frac{\mathrm{n} \pi c}{2 l}\left\{I-\frac{1}{4|\mathrm{n}|\left[\ln \left(\frac{l}{\mathrm{a}}\right)-\ln (2.8|\mathrm{n}|)\right]}\right\} ; \\
& \quad \operatorname{mm} \mathrm{W}_{\mathrm{n}}=\frac{-c}{4 l}\left\{\frac{\ln (2|\mathrm{n}| \pi) \cdot}{\ln \left(\frac{l}{\dot{a}}\right)-\ln (2.8|\mathrm{n}|)}\right\}
\end{aligned}
$$

The $\mathrm{W}_{\mathrm{n}}$ 's represent the string of natural frequencies which is closest to the real w-axis and may. be considered as the principal. natural frequencies. Note that

$$
\operatorname{Re} \mathrm{W}_{-\mathrm{n}}=-\operatorname{Re} \mathrm{W}_{\mathrm{n}}
$$

and

$$
\operatorname{Im} \mathrm{W}_{-\mathrm{n}}=\operatorname{Im} \mathrm{W}_{\mathrm{n}}
$$

Equation (4.I) can be rewritten in terms of positive $n$ for the current at $\mathrm{z}=\mathrm{b}$ as

$$
i(b, t) \approx \sum_{n} K_{n} e^{-\tau} n^{\tau} \sin \beta_{n} t \quad n=1,3 ; \cdots N
$$

where

$$
\begin{aligned}
& \tau_{\mathrm{n}}=-\operatorname{Im} \mathrm{W}_{\mathrm{n}} \\
& \beta_{\mathrm{n}}=\operatorname{Re} \mathrm{W}_{\mathrm{n}}
\end{aligned}
$$

*Values of $N<.05$ l/a gave reasonable results in my calculations. Larger values of $N$ may result in a negative resistance associated with the dipole impedance. 


$$
\dot{\mathrm{K}}_{\mathrm{n}}=\frac{1}{15 \mathrm{n} \pi} \frac{\cos \left(\frac{\mathrm{n} \pi \mathrm{z}}{2 l}\right)}{\ln \left(\frac{4 \ell|z|}{\Gamma^{2} \mathrm{a}^{2} \mathrm{n} \pi}\right)}
$$

In terms of the antenna parameters $\Omega=2 \ln \left(2 \frac{l}{a}\right)$ and $\psi=2 \ln \left(2 \frac{b}{a}\right)$, the inverse time constants can be written as

$$
\tau_{n}=\frac{c}{2 l} \frac{\ln (n)+1.83788}{\Omega-3.44554-2 \ln (n)}
$$

and the resonant radian frequencies are

$$
\beta_{n}=\frac{n \pi c}{2 l}\left\{1-\frac{1}{2 n[\Omega-3.44553-2 \ln (n)]}\right\}
$$

and the constants are

$$
K_{n}=\frac{2}{15 n \pi} \frac{\left.\cos \left(\frac{n \pi}{2}\right) \Lambda\right)}{\Omega+\psi-4.59832-2 \ln (n)},
$$

where

$$
\Lambda=e^{-\frac{1}{2}(\Omega-\psi)}
$$

The Laplace traneform of Eq. (1.6) io

$$
I(b, s) \approx \sum_{n} \frac{K_{n} \beta_{n}}{\left(s+\tau_{n}\right)^{2}+B_{n}^{2}}
$$

The admittanne for a dinnle with a finite gap b as shown in Fig. $3 b$ is approximately $\mathrm{I}(\mathrm{b}, \mathrm{s}) / \mathrm{V}(\mathrm{s}),: \mathrm{V}(\mathrm{s}):=\mathrm{I} / \mathrm{s}$. and can: be written

$$
Y(s) \approx \sum_{n} \frac{s K_{n} \beta_{n}}{\left(s+\tau_{n}\right)^{2}+\beta_{n}^{2}}=\sum_{n} \frac{s C_{n}}{s^{2} L_{n} C_{n}+R_{n} C_{n}+1}, \quad \text { (4.10) }
$$

where

$$
C_{n}=\frac{K_{n} \beta_{n}}{\tau_{n}^{2}+\beta_{n}^{2}}
$$




$$
L_{n}=\frac{1}{K_{n} \beta_{n}}
$$

and

$$
R_{n}=\frac{2 \tau_{n}}{K_{n} \beta_{n}} \text {. }
$$

The dipole admittance is the same as that of $n$ series RIC circuits in parallel as shown in Fig. 4a. The values of the $n^{\text {th }}$. capacitance, inductance, and resistance are given by Eqs. (4.1la), (4.11b), and (4.11c), respectively.

The admittance of a: half-dipole (monopole) antenna is twice that of the dipole antenna. ${ }^{1}$ This can be achieved by the circuit shown in Fig. 4b.

Problems concerning the admittance of a dipole antenna excited by an infinitesimal-gap voltage generator have been solved more exactly by a number of investigators such as R. King, ${ }^{1} \mathrm{C} . \mathrm{W}$. Harrison, ${ }^{9} \mathrm{~S}$. A. Schelkunoff, ${ }^{13}$ C. H. Papas, ${ }^{14}$ T. T. Wu, ${ }^{15}$ and R. Mittra ${ }^{5}$ to mention but a few. However, the solutions are generally not in a simple analytical form except in limiting cases. A comparison of the results from the well known King-Middleton Theory with those from the procedure: outlined above with $N=3$ and $\psi=6$ are shown in Table 3 for $\Omega=10$. From Table 3 it is clear that Eq. (4.10) is a good approximation for the antenna admittance around the first. and third resonances and for small values of $\omega \frac{l}{c}$. Since the short circuit current response of the second and fourth resonances are theoretically zero for $j=0$ (Ref. 4), the admittance at those frequencies are not of much interest. Hence, the admittance calculated by Eq. (4.10) should prove useful for the EMP analysis of dipole and half-dipole antennas that have a fifth resonant frequency above $100 \mathrm{MHz}$ since the bulk of the EMP energy is below 100 MHz. For values of $\Omega>10$, the admittance near the fifth resonance can be calculated by Eq. ( 4.10$)$.

For the electrically short dipole antenna, $\omega \frac{l}{c}<.5$, the antenna impedance can be approximated by ${ }^{1}$

$$
\mathrm{Z}_{\mathrm{a}}=20 \beta_{a}^{2} \ell^{2}\left(1+.133 \beta_{a}^{2} \cdot l^{2}\right)-j \frac{60(\Omega-3 \cdot 39)}{\beta_{a} \ell}
$$




$$
\text { ORNL-DWG 73-7083 }
$$

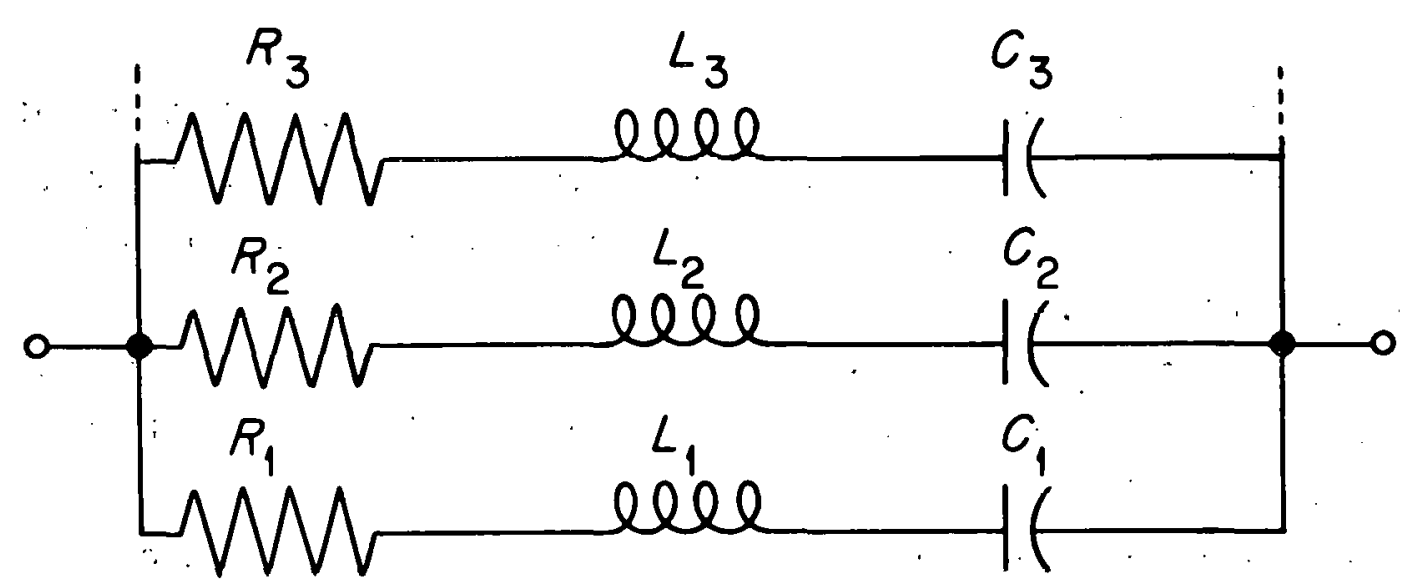

(a) EQUIVALENT CIRCUIT FOR THE CYLINDRICAL DIPOLE ANTENNA

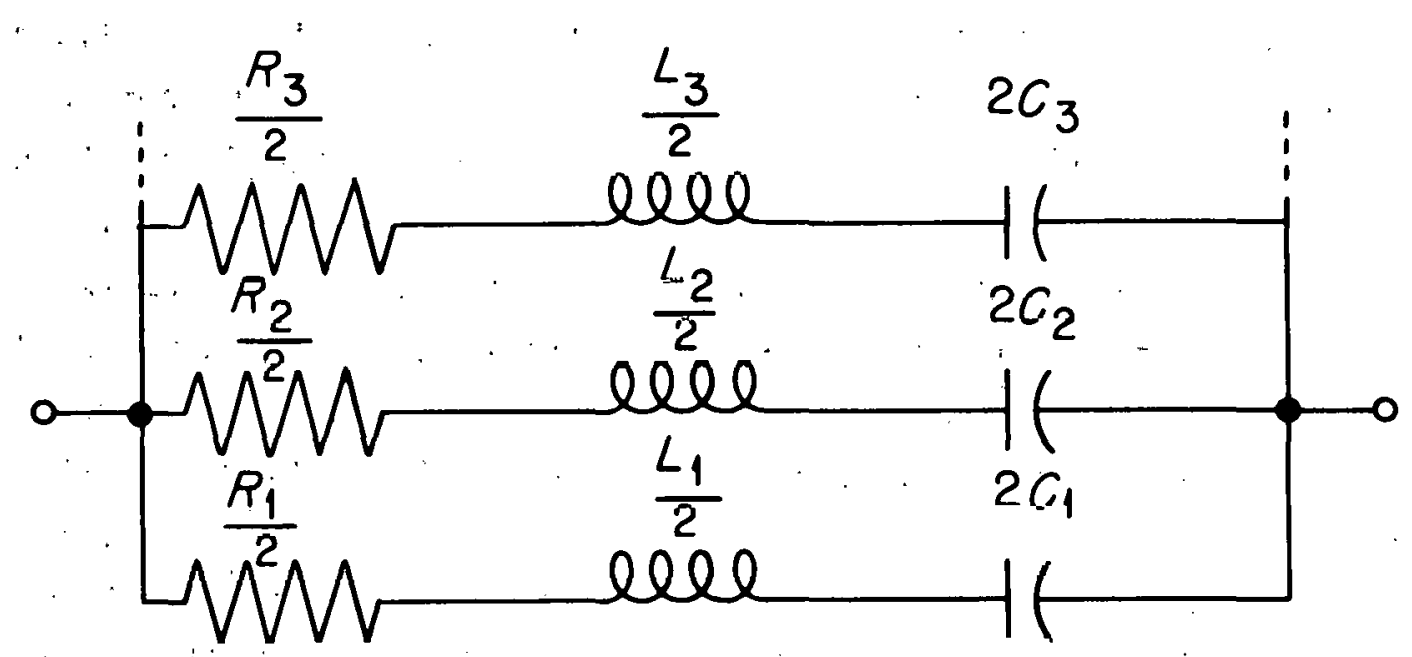

(b) EQUIVALENT CIRCUIT FOR THE CYLINDRICAL HALFDIPOLE ANTENNA

Fig. 4. Equivalent Circuits for the Electric Dipole Impedance and Admittance. 
Table 3... Impedance of a Dipole Antenna with

$$
\begin{gathered}
N=3, \Omega=2 \ln \left(2 l / a^{\prime}\right)=10.0, \text { and } \\
\psi=2 \ln (2 b / a)=6.0 .
\end{gathered}
$$

\begin{tabular}{|c|c|c|c|c|}
\hline$\omega \frac{\ell}{c}$ & $\begin{array}{l}\text { King-M } \\
\text { Secono }\end{array}$ & $\begin{array}{l}\text { Iddletor } \\
\text { d Order }\end{array}$ & $\begin{array}{l}\text { Formul } \\
\text { (invers }\end{array}$ & $\begin{array}{l}\text { la }(4.10) \\
\text { se values) }\end{array}$ \\
\hline .1 & .183 & $-j 3945^{a}$ & $.44 .4=$ & $-j 3613$ \\
\hline$\cdot 3$ & 1.66 & $-j 1274^{a}$ & $44.6=$ & $-j 1163$ \\
\hline .5 & 4.67 & - $\quad j 716$ & $45.0-$ & $-\quad j 647$ \\
\hline .7 & $10 \cdot 3$ & $-\cdots j 451.3$ & $45.8-$ &.$- j 408$ \\
\hline .9 & 18.3 & - j293.8 & $46: 9-$ & - j259 \\
\hline 1.1 & 30.0 & - j177.4. & $48.4-$ & $-\quad j 151$ \\
\hline 1.3 & 47.4 & - $\quad j 79.8$ & $50.6-$ & $j 62.8$ \\
\hline 1.4 & 59.1 & $-\quad j 34.3$ & $52.0-$ & $j 23.2$ \\
\hline 1.5 & 73.6 & $+j 10.3$ & $53.8+$ & $j 14.6$ \\
\hline 2.0 & 240.2 & $+\cdot j 237.1$ & $70.1+$ & j197.2 \\
\hline $2 \cdot 5$ & 820.4 & $+\quad j 71.37$ & $127+$ & $+\quad j 426$ \\
\hline 2.6 & 849.9 & $-j 145.6$ & 154 & $+\quad j 490$ \\
\hline 3.0 & 364.5 & $-j 480.4$ & 505 & $+\quad j 846$ \\
\hline $3 \cdot 5$ & $120 \cdot 9$ & $-j 306.1$ & 1062 & $+\quad j 480$ \\
\hline 4.0 & 70.61 & $-j 160.8$ & 239 & - j226 \\
\hline $4 \cdot 5$ & 86.6 & $-\quad j 17.9$ & 121 & $+\quad j 3 . ?$ \\
\hline 4.6 & $100: 6$ & $+\quad j 12.49$ & 111 & $j 35.2$ \\
\hline
\end{tabular}

${ }^{a}$ Calculated by short antenna formula on p. 19?, Reference 1. 
where

$$
\beta_{a}=\frac{\omega}{c} \quad
$$

For the purpose of comparison, three methods of calculating the antenna static capacitance are given below. From Eq. (4.12) the antenna capacitance is

$$
\mathrm{c}_{\mathrm{a}}=\frac{100 \ell}{1.8(\bar{\Omega}-3.39)} \mathrm{pf}
$$

which has a value of 8.40 \& pf for $8-10$.

From Eq. (4.1la) the contribution of the first term to the antenna capacitance for $\Omega=10$ and $\psi=6$ is

$$
C_{1}=\frac{K_{1} \beta_{1}}{\tau_{1}^{2}+\beta_{1}^{\vec{a}}},
$$

which has a value of $8.28 \cdot \ell$ pf for $\ddot{\Omega}=10$.

And from Eq. (3.5), the low frequency asymptotic form for $\Omega=10$ is

$$
I(l, s) \sim \mathrm{H}_{\mathrm{o}} l \frac{\mathrm{A}_{1} B_{1}+\ldots \omega_{1}}{\gamma_{1}^{2}+\omega_{1}^{2}}=8.19 \mathrm{E}_{\mathrm{o}} \ell^{2} \times 10^{-12}=\mathrm{E}_{\mathrm{o}} l_{\mathrm{eq}} \mathrm{C}_{\mathrm{a}}
$$

For the electrically short dipole antenna the effective length is given on page 470 of Reference 1 as left $\approx$. 36.6 . Alon for the eleotrically short antenna $l_{\mathrm{eq}} \approx l_{\text {eff' }}$ thus the antenna capacitance as calculated from. Eq. (4.15) is

$$
\mathrm{C}_{\mathrm{a}}=\frac{8.19 \cdot \mathrm{E}_{0} l^{2} \times 10^{-1 . z}}{.96 \mathrm{E}_{0} l}=8.52 \ell \mathrm{pf} .
$$

The relative difference between the three methods of calculating the antenna capacitance is less than three percent.

Although the reactance of the antenna impedance as calculated from the inverse of the admittance given by Eq. (4.10) is in reasonable agreement with antenna theory, the resistance differs by a considerable amount. The correct value of the resistance is most important near the first and third resonances since the magnitude of the reactance is small at those 
frequencies. The theoretical value of the resistance of an infinitely thin dipole at the first resonant frequency is 73.13 ohms. ${ }^{9}$ For $\Omega_{2}=10$, the resistance is about 82.8 ohms. For most thin antenna analyes, a value for $R_{1}$ of 80 ohms should give reasonable results. Also a value for $R_{3}$ of 120 ohms can be used for thin dipole antennas, $i . e_{.}, \Omega$ in the range of 10 . to 20 .

The values of the normalized antenna equivalent circuit elements for a wide range of $\Omega$ are shown in Table 4 for $\psi=6$. Equation (4.11) was used for the calculations.

\section{THE OPEN-CIRCUIT VOLTAGE}

The open-circuit antenna voltage can be computed from Eq. (2.3) and is given by

$$
V_{a}(s)=\frac{I_{a}(s)}{Y_{a}(s)}
$$

The short-circuit current can be accurately calculated by the expressions given in Section III; however, the antenna admittance given in Section IV is only an approximate solution good for frequencies near the first and third resonances and low frequencies. Therefore, the solution for $\mathrm{V}_{\mathrm{a}}(\mathrm{s})$ given in this section must be an approximation to the same order of accuracy as the expression used for $\mathrm{Y}_{\mathrm{a}}(\mathrm{s})$.

The antenna current response to an impulse incident plane wave with the electric field $E(s)=E_{0}$ parallel to the antenna is given by

$$
I_{\delta}(s)=4 E_{o} l s \sum_{m=1}^{M} \frac{A_{m}\left(s+\gamma_{m}\right)+B_{m} \omega_{m}}{\left(s+\gamma_{m}\right)^{2}+w_{m}^{2}} \text {, }
$$

where Eq. (3.5) with $\mathrm{z}=0$ has been used.

Substituting Eqs. (5.2) and (4.10) into (5.1) gives

$$
V_{\delta}(s)=4 E_{\delta} l \frac{\sum_{m=1}^{M} \frac{A_{m}\left(s+\gamma_{m}\right)+B_{m} \omega_{m}}{\left(s+\gamma_{m}\right)^{2}+\omega_{m}^{2}}}{\sum_{n=1}^{N} \frac{K_{n} \beta_{n}}{\left(g+\tau_{11}\right)^{2}+B_{n}^{2}}} .
$$


Table 4. Equivalent Cireuit Elements for the Dipole Antenra Admittance with $\psi=2 \ln (2 b / a)=6$.

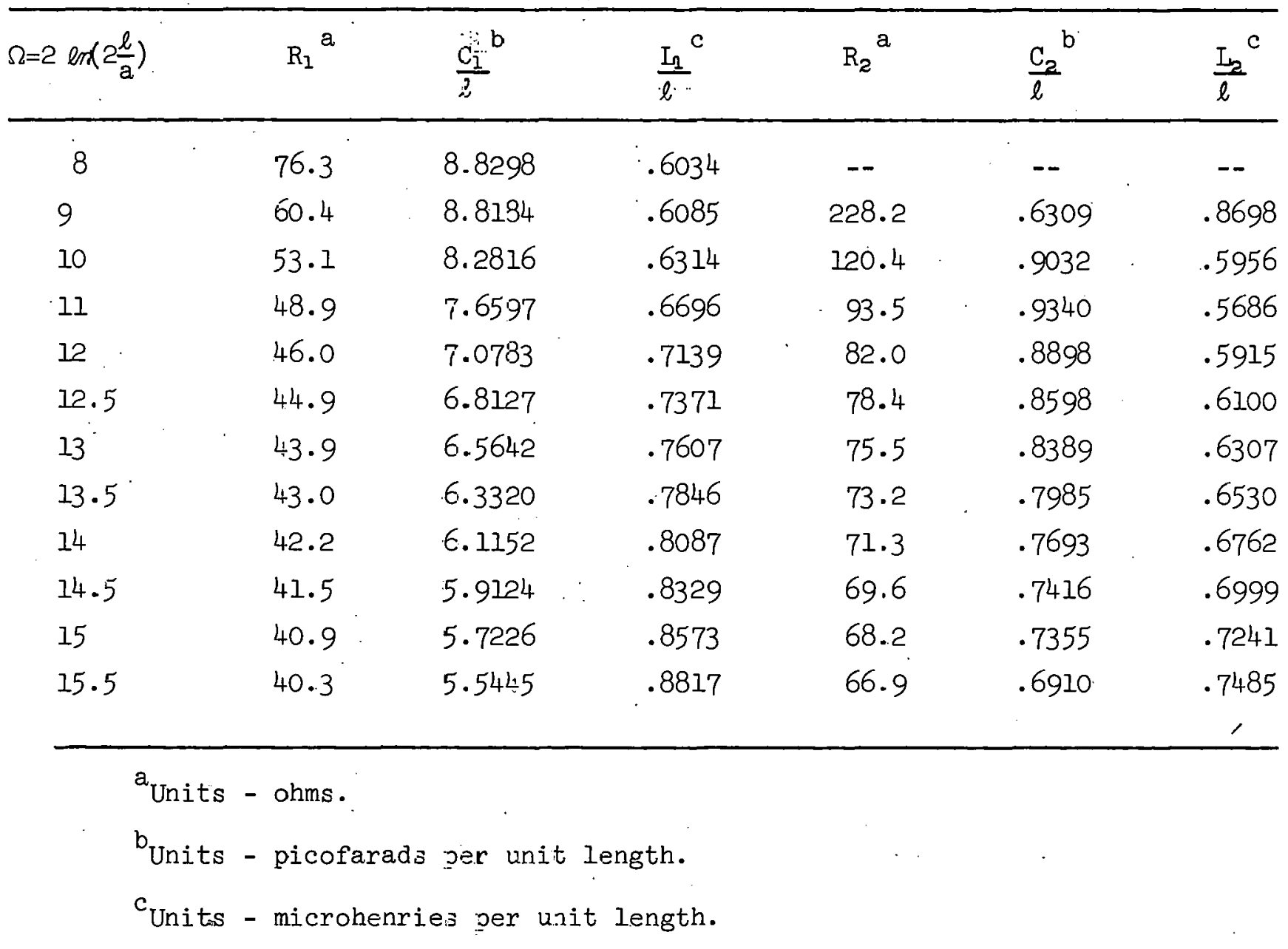


In Reference 3, it was shown that the natural frequencies are a function of the object and not the source. The natural frequencies are also unique. Thus, theoretically $\tau_{n} \equiv \gamma_{m}$ and $\beta_{n} \equiv \omega_{m}$ for $n=m$ and Eq. (5.3) can be written as

$$
\mathrm{V}_{\delta}(s)=4 \cdot \mathrm{E}_{0} l \cdot \frac{\sum_{\mathrm{m}=1}^{M} \frac{A_{m}\left(s+\gamma_{m}\right)+B_{m} w_{m}}{\left(s+\gamma_{m}\right)^{2}+w_{m}^{2}}}{\sum_{m=1}^{N} \frac{K_{m} \omega_{m}}{\left(s+\gamma_{m}\right)^{2}+w_{m}^{2}}}=E_{o} l \text { eff }\left(\frac{\pi}{2}, s\right) \cdot(5 \cdot 4)
$$

A first order solution for the effective length can be obtained from Eq. (5.4) by recalling that for late times (small s) only the first terms in the series expressions for the current and admittance are important. Considering only the first terms gives

$$
i_{\text {eff }}=4 \ell\left[\frac{A_{1}\left(s+\gamma_{1}\right)+B_{1} \omega_{1}}{K_{1} w_{1}}\right]=l_{e q}+s l_{e}
$$

where

and

$$
\ell_{e q}=4 \ell\left(\frac{A_{1} \gamma_{1}+B_{1} \omega_{1}}{K_{1} \omega_{1}}\right)
$$

$$
\ell_{e}=\frac{4 \ell A_{1}}{K_{1} \omega_{1}}
$$

For $\Omega=10$ and $\psi=6, \ell_{\text {eq }}=.963 \mathrm{l}$ and $\ell_{e}=.1255 \frac{\ell^{2}}{c} \cdot$ The result for $\ell_{\text {eq }}$ obtained by $\mathrm{King}^{2}$ for a very small gap is $\ell_{\text {eq }}=.958 \ell^{*}{ }^{*}$

As $\Omega \rightarrow \infty$ the equivalent length approaches $l$. An upper bound for the open-circuit voltage up to the first resonance for the thin antenna can be written as

$$
V_{\delta}(s)=E_{o} l\left[1+s \sum_{m} \frac{A_{m}}{A_{m} \gamma_{m}+B_{m} \omega_{m}}\right] \text {. }
$$

*The comparison of the effective lengths are not made for equal gaps because the theory presented in Section IV does not apply for the small gap range. 
Note that the voltage is not a function of the antenna gap; however, the assumption is that the gap is small; ${ }^{*} b \ll$ a, such that $l e q \approx l$. From Eq. (5.6a) it can be seen that $K_{1} \approx 4 B_{1}$ (for small gap lengths) for the thin dipole with a very small gap since $B_{1} \omega_{1} \gg A_{1} \gamma_{1}$. This permits another method for the calculation of the equivalent circuit elements for the first resonances of the thin dipole. The substitution of $\omega_{1}=\beta_{1}$, $\gamma_{1}=\tau_{1}$ and $K_{1}=4 B_{1}$ in Eq. (4.11) gives

$$
\begin{aligned}
& C_{1}=\frac{4 B_{1} \omega_{1}}{3 \beta+\omega_{1}^{2}} \\
& I_{1}=\frac{1}{4 B_{1} \omega_{1}} \\
& R_{1}=\frac{\gamma_{1}}{2 B_{1} \omega_{1}} .
\end{aligned}
$$

The open circuit antenna voltage response to the incident electric field $E(t)$ can be calculated from Eq. (5.4) as

$$
v_{a}(t)=\ell_{e q} E(t)+\ell_{e} \frac{\partial E(t)}{\partial t}
$$

where $\ell_{e q}$ and $\ell_{e}$ are determined from Eq. (5.6 a ) and (5.6) respectively.

\section{TRANSIENT RESPONSE AT THE LOAD}

The transient response at the antenna's load can be calculated from Eqs. (2.1) and (2.2). The voltage across the load is

$$
v(t)=L^{-1}\left\{\frac{I_{a}(s)}{\bar{Y}_{a}(s)+Y_{L}(z)}\right\}
$$

and the current through the load is

$$
i(t)=L^{-1}\left\{\frac{I_{a}(s) Y_{L}(s)}{Y_{Q}(s)+Y_{L}(s)}\right\},
$$


where $L^{-1}\{F(s)\}$ is the inverse Laplace transformation of a function $F(s)$ and $Y_{L}(s)$ is the Laplace transform representation of the load admittance.

If it is assumed that $Y_{L}$ is a matched tuned band-pass filter load such that $\mathrm{Y}_{\mathrm{L}}=\mathrm{Y}_{\mathrm{a}}$ for a narrow band of frequencies centered about the first resonance, the load voltage response can be written for the stepfunction incident field as

$$
v(t)=\left.\frac{i_{a}(t) R_{L}}{2}\right|_{m=1},
$$

and the load current is

$$
i(t)=\left.\frac{i_{a}(t)}{2}\right|_{m=1}
$$

The power dissipated in the load is

$$
\begin{gathered}
P=\left.\frac{i_{a}^{2}(t)}{4} R_{L}\right|_{m=1}= \\
4 E_{0}^{2} l^{2} R_{L} e^{-2 \gamma_{1} t}\left(A_{1} \cos \omega_{1} t+\beta_{1} \sin \omega_{1} t\right)^{2} \approx \\
4 E_{0}^{2} l^{2} \cdot R_{L} B_{I}^{2} \cdot e^{-2 \gamma_{1} t} \sin ^{2} \omega_{I} t,
\end{gathered}
$$

where the property that $B_{m}$ is normally an order of magnitude larger than the $A_{m}$ has been used to obtain the approximate expression. The energy received during the first half-cycle is approximately

$$
\begin{aligned}
E_{n} & =4 E_{0}^{2} l^{2} R_{L} B_{1}^{2} \int_{0}^{\pi / 2 \omega_{1}} e^{-\gamma_{1} t} \sin ^{2} \omega_{1} t d t \\
& =4 E_{0}^{2} l^{2} R_{L} B_{1}^{2} \frac{\omega_{1}^{2}\left(1-\exp \left(\frac{\gamma_{1} \pi}{\omega_{1}}\right)\right.}{\left(4 \gamma_{1}^{2}+4 \omega_{1}^{2}\right) \gamma_{1}} \\
& \approx E_{0}^{2} l^{2} R_{L} B_{1}^{2} \frac{\pi}{\omega_{1}}=\frac{E_{0}^{2} l^{2} B_{1}^{2} R_{L}}{2 f_{0}},
\end{aligned}
$$


where the relations $\omega_{1}=2 \pi f_{0}$ and $\omega_{1} \gg \gamma_{I}$ have been used.

If the dipole is a quarter wavelength antenna (wavelength $=4 \ell$ ),

Eq. (6.6) becomes

$$
E_{n} \approx \frac{E_{0}^{2} c^{2} B_{1}^{2} R_{L}}{32 \mathrm{f}_{0}^{3}}
$$

To the same approximation, the peak value of the load current for the antenna is

$$
i_{m} \approx 2 E_{0} \& B_{1}=\frac{E_{0} B_{1} c}{2 f_{0}} .
$$

If it is assumed that $\mathrm{Y}_{\mathrm{L}}$ is a parallel resistor, capacitor, and inductor tank circuit resonant at $\omega_{0}=\omega_{I}$ such that $Y_{L}^{-1} \approx R_{L}$ for frequencies near resonance, the load current response for $M=I$ is

$$
\begin{aligned}
I(s) & =\frac{4 E_{0} \ell B_{1} \omega_{1}}{\left(s+\gamma_{1}\right)^{2}+\omega_{1}^{2}} \times \frac{\frac{1}{R_{L}}}{\frac{1}{R_{L}}+\frac{s K_{1} \beta_{1}}{\left(s+\tau_{1}\right)^{2}+\beta_{1}^{2}}} \\
& =4 E_{0} \ell B_{1} \frac{1}{\sqrt{1-4 R_{1} B_{1} \frac{\gamma 1}{\omega_{1}}-4 R^{2} B_{1}^{2}}} \times \frac{\omega_{1}}{\left(s+\gamma_{1}^{\prime}\right)^{2}+\left(\omega_{1}^{\prime}\right)^{2}}
\end{aligned}
$$

where

$$
\gamma_{i}^{\prime}=\gamma_{1}+e_{I} B_{I}(1)
$$

and

$$
\left(\omega_{1}^{\prime}\right)^{2}=\omega_{1}^{2}-4 R_{L} \omega_{1} B_{1} \gamma_{1}:-4 R_{I}^{2} B_{1}^{2} \omega_{1}^{2},
$$

and the approximate relations $\omega_{1}=B_{1}, \gamma_{1}=\tau_{1}$, and $4 B_{1}=K_{1}$ have been used. For. $\mathrm{R}_{L^{\prime}} \mathrm{B}_{1} \ll 1$, $\omega_{1}^{\prime} \approx \omega_{1}$ and

$$
I(\varepsilon) \approx l_{1} E_{0} \& B_{1} \frac{\omega_{1}}{\left(s+\gamma_{1}^{\prime}\right)^{\frac{1}{2}}+\omega_{1}^{2}}
$$


The load current is given in the time domain as

$$
i(t) \approx 4 E_{0} \& B_{1} e^{-\gamma_{1}^{\prime} t} \sin \omega_{1} t
$$

The peak value of the load current is

$$
i_{m} \approx 4 \mathrm{E}_{\mathrm{o}} \quad \ell \mathrm{B}_{1} \mathrm{e}^{-\frac{\gamma_{1}^{\prime} \pi}{2 \omega_{1}}}
$$

The energy received by the resistive element of the load during the first half-cycle is

$$
\begin{aligned}
E_{n} & =\int_{0}^{\frac{\pi}{2 \omega_{1}}} i^{2}(t) R_{L} d t=16 \mathrm{E}_{0}^{2} l^{2} \mathrm{R}_{L} \mathrm{~B}_{1}^{2} \frac{\omega_{1}^{2}\left[1-\exp \left(-\gamma_{1}^{\prime} \frac{\pi}{\omega_{1}}\right)\right]}{\left(4 \gamma_{1}^{\prime 2}+4 \omega_{1}^{2}\right) \gamma_{1}^{\prime}} \\
& \approx 4 \mathrm{E}_{0}^{2} l^{2} \mathrm{~B}_{1}^{2} \mathrm{R}_{L} \frac{\pi}{\omega_{I}}
\end{aligned}
$$

For the quarter wavelength antenna (half wavelength long dipole), the resuits are

$$
E_{n} \approx \frac{E_{0}^{2} c^{2} \cdot B_{1}^{2} R_{L}}{8 f_{0}^{3}}
$$

and

$$
1_{m} \approx \frac{E_{O} c B_{1}}{f_{0}} \exp \left(-R_{L} B_{1} \pi-\frac{\gamma_{1}}{4 f_{0}}\right)
$$

The preceding discussion in this section has been limited to the . electric dipole antenna. Equations (6.1) through (6.16) can be applied to an electric half-dipole (monopole) antenna by replacing $\mathrm{E}_{\mathrm{o}}$ with $2 \mathrm{E}_{\mathrm{O}}$ in the equations. This is necessary because the total electric field at the antenna is the sum of the free space incident field plus the image field as shown in Fig. $2 b_{0}^{*}$

\footnotetext{
* The angle of incidence is broadside to the antenna; $\theta=\frac{\pi}{2}$.
} 
The impedance of the half-dipole antenna $z_{\dot{a}}$ is one-half that of the dipole impedance $Z_{a d}$ and the short circuit current of the half-dipole $I_{a h}$ is twice that of the dipole current $I_{a d}$; thus, the open circuit halfdipole voltage $V_{a h}$ is related to the open circuit dipole voltage $V_{a d}$ by

$$
V_{\text {ad }}=I_{\text {ad }} Z_{\text {ad }}=\frac{\left(I_{a h}\right)}{2}\left(2 z_{a h}\right)=V_{a h} \text {. }
$$

The power dissipated in a matched load of the half-dipole antenna is

$$
P_{h}=\frac{I_{a h}^{2} R_{L h}}{4}=\frac{I_{a d}^{2} R_{L d}}{2}=2 P_{d}
$$

where $R_{L h}$ is the resistance of a matched half-dipole resonant load and $R_{L d}$ is the resistance of a matched dipole resonant load. The power received by the matched dipole load $P_{d}$ is one-half that received by the half-dipole load $P_{n}$, thus the power gain of the half-dipole antenna reference to a dipole is 2 or $3 \mathrm{db}$.

As an example calculation to demonstrate the application of the technique presented in this paper, the normalized current response has been calculated for a half-dipole antenna with $\Omega=2$ ln $\left(2 \frac{l}{a}\right)=12.5$. The angle of incidence of the incident EMP is $\frac{\pi}{2}$ measured from the axis of the antenna. And the electric field is parallel to the half-dipole.

In Fig. 5, the normalized short circuit current responses are plutted against time. The waveform shown in Fig. 5a is the response to an indicent wave with a step-function time history. In Fig. 5b, the normalized short circuit current response to an incident field with a double exponential waveform is plotted for a one-meter-long half-dipole. The values for the plots in Fig. 5 were calculated from Eq. (3.10) with $M=5$.

In Fig. 6, the normalized load current response of a one-meter halfaipole to a double exponential EMP is plotted for a resistive and tuned load. The resistive load is a 50-ohm resistor. The tuned load is a parallel RIC tank circuit with $R=50$ ohms, $L=.1$ microhenries, and $\mathrm{C}=50$ picofarads. The tuned circuit is resonant at frequencies near but not exactly the first resonant frequency of the antenna. The values for the plots in.Fig. 6 were calculated from Eq. (6.2) using an inverse 


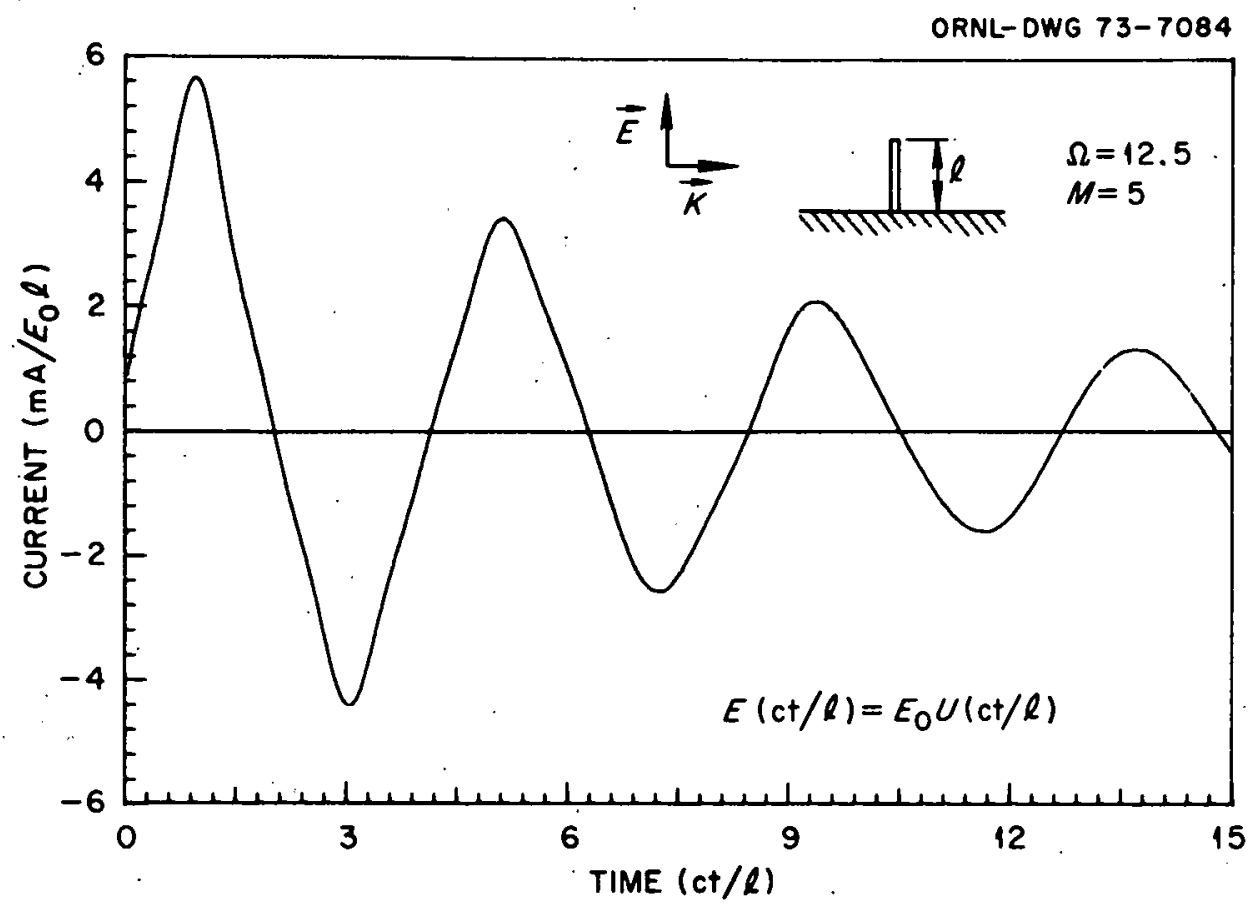

(a) RESPONSE TO A STEP-FUNCTION EMP.

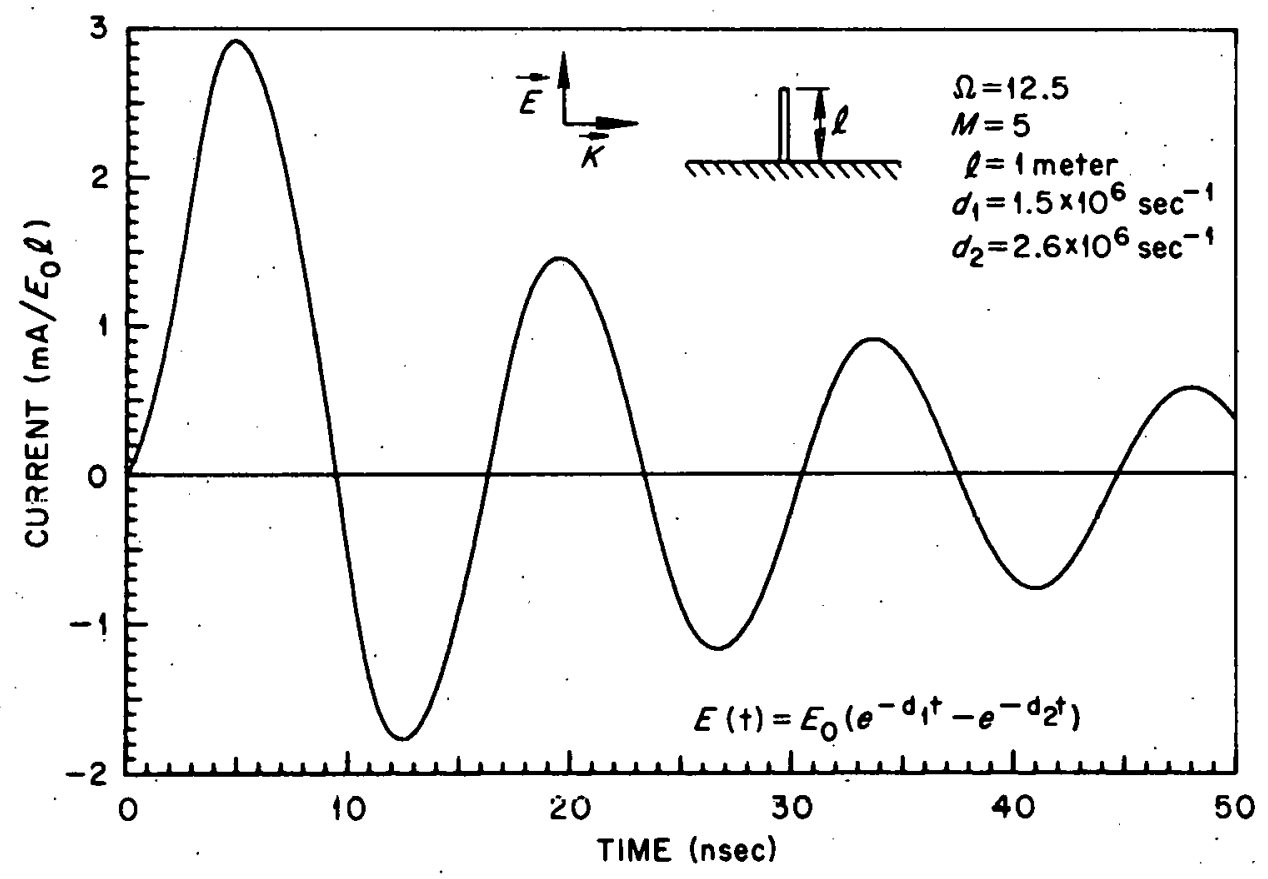

(b) RESPONSE TO A DOUBLE EXPONENTIAL EMP.

Fig. 5. Short Circuit Current Response of a Half-Dipole Antenna to EMP. 


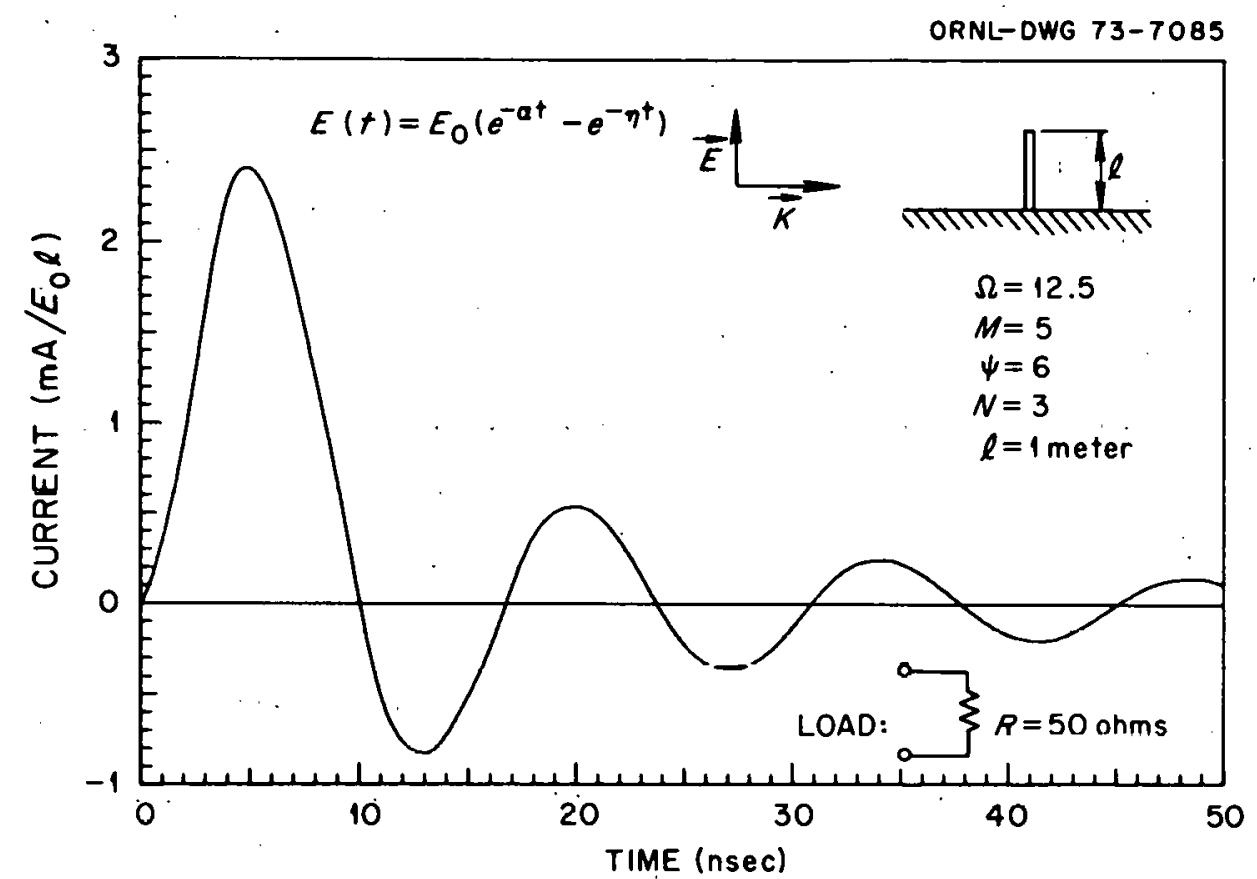

(a) À 50ohm RESISTIVE LOAD

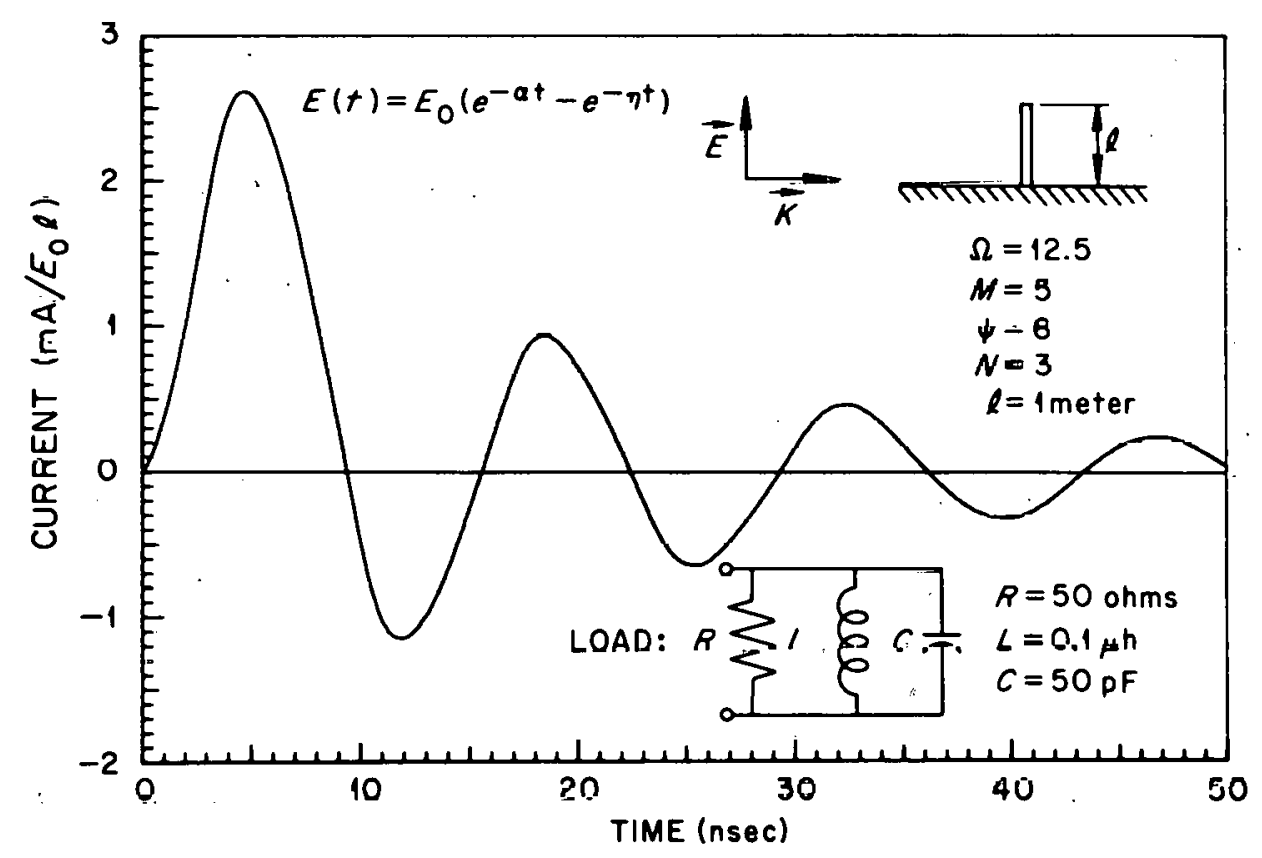

(b) A PARALLEL R-L-C LOAD

Fig. 6. Load Current Response of a Half-Dipole Antenna to a Duuble Exponential EH with $\alpha_{2}=1.5 \times 10^{\circ} \mathrm{sec}^{-1}$ and $\alpha_{2}=2.6 \times 10^{8}$ $\sec ^{-1}$. 
Laplace transformation program supplied by James H. Marable of ORNL. The frequency domain antenna short circuit current was calculated from Eq. (3.5) with $\mathrm{M}=5$ and the antenna admittance was obtained from Eq. (4.10) with $N=3$ and $\psi=6$.

The double exponential waveform used in the calculations is of the form $e^{-\alpha_{1} t}-e^{-\alpha_{2} t}$ with $\alpha_{1}=1.5 \times 10^{5} \mathrm{sec}^{-1}$ and $\alpha_{2}=2.6 \times 10^{8} \mathrm{sec}^{-1}$. The pulse has a rise time of about 10 narroseconds and fall time of about 2.5 microseconds.

The current response through a 75-ohm load connected to a cylindrical dipole antenna excited by a unit step function plane wave pulse is shown in Fig. 7. The solid curve is the response calculated by the singularity expansion method as presented in this paper. The dashed curve is the response calculated by classical antenna theory as employed by David B. Nelson. ${ }^{10}$ The program used by Nelson was developed by Toulious et al. $;^{11}$ it employs classical antenna theory and numerical techniques to calculate the time response of a cylindrical dipole to a. transient plane wave. The two curves compare reasonably well as can be seen in Fig. 7.

\section{SIMULATION}

The simulation of the effects of the nuclear electromagnetic pulse is useful to determine the response of complex systems to EMP and to correlate experimental and theoretical results of EMP interaction with less complex systems. Also, manufacturers can utilize the simulation of EMP effects on their products to design for and meet EMP specifications. The simulativil of the effects of "kMP can be classified into two categories: system-level and partial system-level simulators. The system-level simulators are generally bounded-wave parallel-plate waveguides, electric- or magnetic-dipole radiating structures, distributedsource structures, or some combination thereof which illuminates the entire system being tested. The free-field environment of the systemlevel simulator has the advantage that only the free field has to be known to conduct a high quality test providing the system being tested does not distort the free-field environment. Also, if the total system is contained within the free-field environment, all the natural modes 


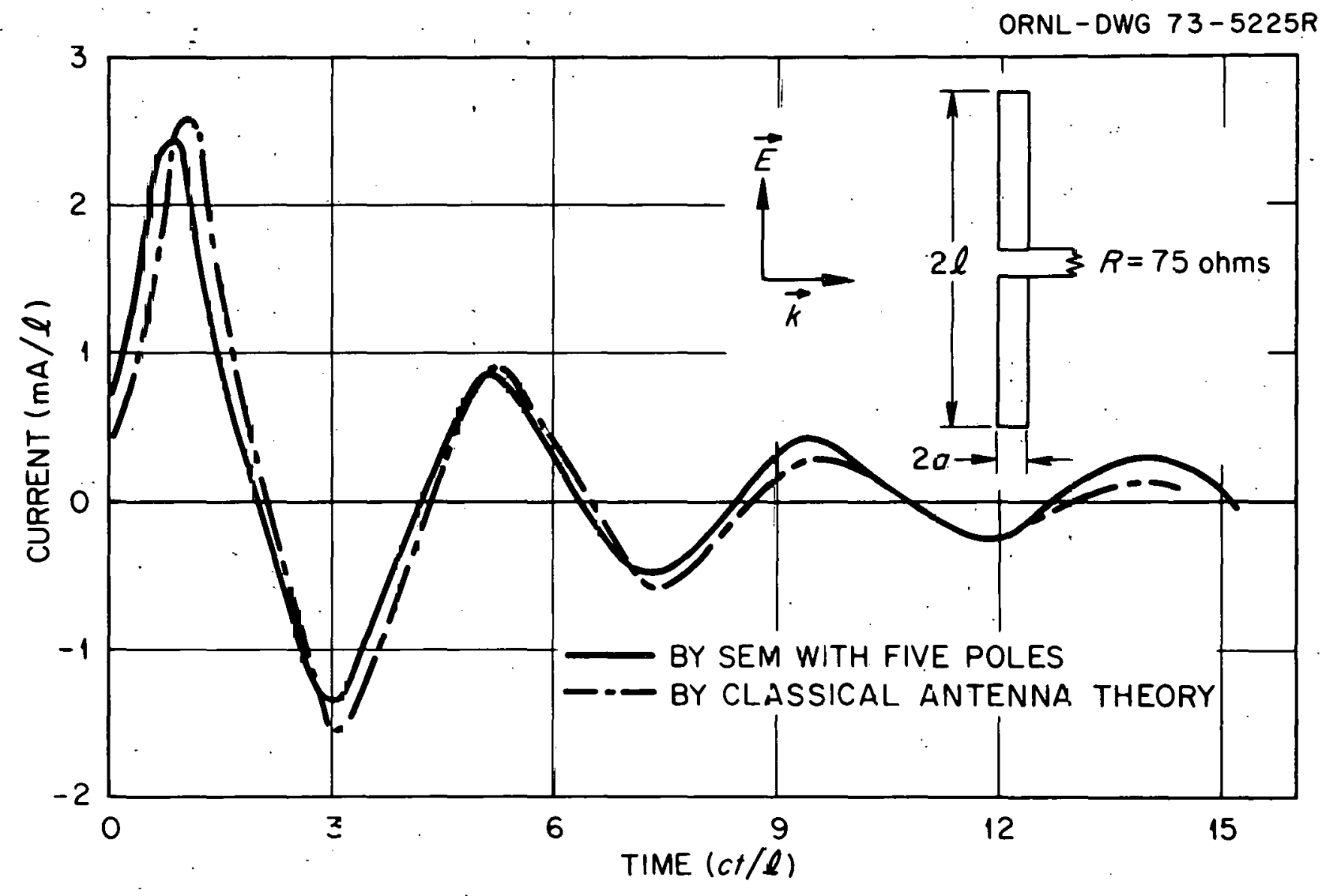

$\stackrel{\omega}{\leftarrow}$

Fig. 7. The Nornalized Current Through a 75 ohm Resistive Load Connectec to a Cylindrical Dipole Anten la Excited by a Unit Step Function Plane. Weve Pulse. 
are excited in the same manner as they would be in the actual EMP. . environment.

The partial system-level simulators excite only portions of a system such as appendages or points of entry. The partial system-level simulators often employ the pulse injection technique which has the disadvantage that the pulse being simulated has to be known or at least approximately known. This requires either a previous free-field test or EM system interaction studies. Also, only one or several EM coupling mechanisms are simulated and it is often difficult to correctly simulate all the natural modes for any single coupling mechanism. However, the partial system-level EMP simulator can be a useful tool in determining the degradation effects of EMP energy at a particular point of entry. It also, in general, has the advantages of being lower in cost, less complex, more transportable, and requires less physical space than the system-level simulator.

The simulator designs presented here are the pulse injection type intended to simulate the major effects of EMP interaction with a halfdipole (monopole) antenna. The first pulser design is for the simulation of a double exponential. EMP and the second and third designs are for the simulation of a step-function EMP.

Only the first mode and the low frequency response is simulated by the double-exponential EMP simulator. This is a fairly good simulation since the third mode is smaller than the first by nearly an order. of magnitude.

For the half-dipole, the equivalent length is one-half that of the dipole. However, the electric field at the antenna is twice the incident field due to the ground plane reflection for $\theta=\frac{\pi}{2}$. Thus, from Eq. (5.9) the open-circuit voltage is given approximately by

$$
V_{a}(t) \approx l E(t)=l E_{0}\left(e^{-\alpha_{1} t}-e^{-\alpha_{2} t}\right)
$$

where the relation $\ell \approx \ell_{\text {eq }}$ has been used. The double exponential EMP is assumed to have a fast rise time such that $\alpha_{2} \gg \dot{\alpha}_{1}$. The Laplace transformation of the open circuit voltage is

$$
\mathrm{V}_{\mathrm{a}}(\mathrm{s}) \approx \mathrm{E}_{0} l \frac{\alpha_{2}-\alpha_{1}}{\left(\mathrm{~s}+\alpha_{1}\right)\left(\mathrm{s}+\alpha_{2}\right)} \approx \frac{\mathrm{E}_{0} l \alpha_{2}}{\left(\mathrm{~s}+\alpha_{1}\right)\left(\mathrm{s}+\alpha_{2}\right)}
$$


This voltage can be obtained by a series circuit consisting of a charged capacitor that is discharged through a resistor and a special non-ideal switch. The normalized voltage response of the non-ideal switch when connected to a constant voltage source is given by

$$
\mathrm{V}_{\mathrm{sw}}(\mathrm{s})=\frac{\alpha_{2}}{s \cdot\left(\mathrm{s}+\alpha_{2}\right)}
$$

If the source capacitor $\mathrm{C}_{\mathrm{S}}$ is charged to a voltage $\mathrm{E}_{\mathrm{O}} \dot{\mathrm{l}}$, the voltage across the discharging resistor $R_{s}$ with the non-ideal switch is the desired antenna voltage given by Eq. (7.2) where $\alpha_{1}=\left(\mathrm{R}_{\mathrm{S}} \mathrm{C}_{\mathrm{s}}\right)^{-1}$.

The circuit to approximate the Thevenin equivalent circuit for the half-dipole is shown in Fig. 7a. The antenna circuit elements are given by

$$
\begin{aligned}
& C=\frac{8 B_{1} \omega_{1}}{\gamma_{1}^{2}+\omega_{1}^{2}}, \\
& L=\frac{1}{8 B_{1} \omega_{1}},
\end{aligned}
$$

and

$$
R=\frac{\dot{y}_{1}}{4 B_{1} \omega_{1}}
$$

The source capacitance $\mathrm{C}_{\mathrm{g}}$ and the source resistance $\mathrm{R}_{\mathrm{S}}$ should be selected such that $C_{S} \gg\left(\omega_{0} R\right)^{-1}$ and $R_{S} \ll R$ to achieve the correct input impedance. To meet this requirement it is necessary that $\omega_{0} \gg \alpha_{1}$.

The charging resistor $R_{c}$ should be large enough to provide currentlimiting protection for the high voltage power supply. Also, $R_{c}$ should be much greater than $R_{3}$ to allow the capacitor $C_{5}$ to discharge tin ai $1 n w$ potential.

To simulate a step-function incident field $E_{O} U(t)$, set $\alpha_{2}$ and $R_{S}$ equal to infinity in the pulser circuit shown in Fig. 8a. The pulser will simulate the dominant sinewave mode for several cycles until the waveform exponentially decays to zero. However, for most applications of determining component failure, only the positive (or negative) portion of the first cycle of the waveform is important. 


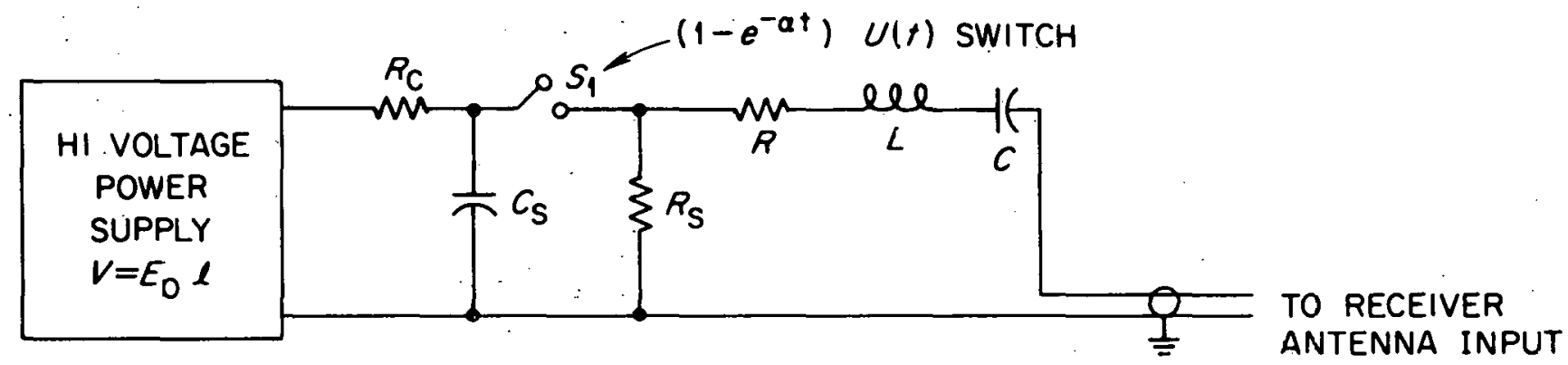

(a) PULSER TO SIMULATE A DOUBLE-EXPONENTIAL EMP

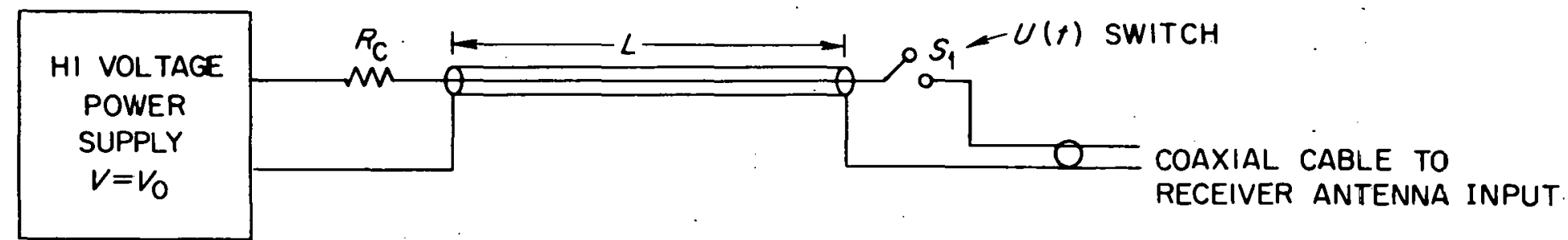

(b) PULSER TO SIMULATE A STEP-FUNCTION EMP

Fib. 8. Pulsers for Simulating the Half-Dipole Antenna Response to EMP. 
Consider the pulser consisting of a charged coaxial cable of length I as shown in Fig. 8b. If the load input impedance and the cable characteristic impedance $z_{0}$ are equal, the current through the load is ${ }^{1}$ ?

$$
i_{c}(t)=\frac{V_{0}}{2 Z_{0}}\left[U(t)-U\left(t-\frac{2 L}{\nu}\right)\right] \text {, }
$$

where $V_{O}$ is the initial cable voltage and $\nu$ is the velocity of propagation for the cable. Equation $(7.5)$ can be reqritten as

$$
i_{c}(t)=\frac{V_{0}}{2 Z_{0}} \frac{4}{\pi}\left(\sin \frac{\pi v t}{2 L}+\frac{1}{3} \sin \frac{3 \pi v t}{2 L}+\cdots\right) 0 \leq t \leq \frac{2 L}{\nu} .
$$

The current response through a parallel resistor, capacitor, and inductor tank circuit load is given by Eq. (6.12) as

$$
i(t) \approx 4 E_{0} l e^{-\gamma_{1}^{\prime} t} B_{1} \sin \omega_{1} t:
$$

Noting that $\omega_{1} \gg \gamma_{1}$, Eq. $(7.7)$ can be approximated over the first cycle for a half-dipole as

$$
i(t) \approx 8 E_{0} l B_{1} \sin \omega_{1} t \quad 0 \leq t \leq \frac{\pi}{\omega_{1}} .
$$

For the narrow bandpass, tuned load with a center bandpass radian frequency $\omega_{1}=\frac{\pi \nu}{2 L}$, only the first term in the expansion given by $E q$. (7.6) constitutes the current through the load. Equating the first term in Eq. (7.6) with Eq. (7.8) gives

$$
V_{0}=4 E_{0} \& \pi B_{1} Z_{0}
$$

and

$$
L=\frac{\pi \nu}{2 \omega_{1}}
$$

The coaxial cable between the pulser switch and the receiver should be longer than length $\mathrm{L}$ such that the source cable can discharge into load equal to the characteristic impedance of the cable for the duration of the pulse. Also, the charging resistor $R_{C}$ should be large to provide 
current-limiting protection for the high voltage power supply. In order not to distort the waveform, $R_{C}$ should be selected such that $R_{c} \gg 2 Z_{0}$. The value of $R_{c}$ that is required to provide current-limiting protection will normally satisfy the second condition.

Now consider a third pulse injection technique that employs the antenna to provide its own antenna Thevenin impedance as shown in Fig. 9. This technique has two advantages over the other two methods presented in this chapter: (1) the exact Thevenin equivalent impedance is used and (2) certain non-linear effects such as spark-over from the antenna to ground, corona, etc. are also included in the circuit.

A pulser circuit to provide a first-order antenna Thevenin equivalent voltage source due to a step-function EMP $E(t)=E_{O} U(t)$ is shown in Fig. 9b. Switch $S_{1}$ is used to isolate the load impedance $Z_{L}$ while the source capacitor is charging. Once $\mathrm{C}_{S}$ is charged, $\mathrm{S}_{1}$ is closed and then the low-inductance, fast-rise switch $S_{2}$ is closed to apply an approximate step-function voltage source between the antenna and the load. The source capacitance $C_{S}$ should be chosen such that $C_{S} \gg C_{1}$ so that the series impedance of the antenna and $C_{S}$ as viewed from $S_{1}$ is approximately the same as the antenna impedance. $C_{S}$ can be chosen such that

$$
\frac{C_{s}}{\ell} \geq 1 \quad \text { nanofarads/meter }
$$

For $\ell \leq 10$ meters, a value of $\mathrm{C}_{\mathrm{S}}=.01 \mu \mathrm{f}$ will provide adequate capacitance. The charging resistors $R_{c}^{\prime}$ 's should be large enough to provide current-limiting protection for the power supply and to isolate the power supply from the antenna-load circuit once $S_{2}$ has been closed.

\section{SUMMARY}

In this paper, a new technique to calculate the electric dipole antenna short-circuit current, open-circuit voltage, and load current and voltage responses to EMP has been considered. Basically, it involves applying the results of the singularity expansion method which expands the time-domain solution of the electromagnetic quantity such as the short-circuit current, etc. in terms of simple analytic functions. Each term comes from an inverse transform of the corresponding term in the 
ORNL-OWG $73-7097$.

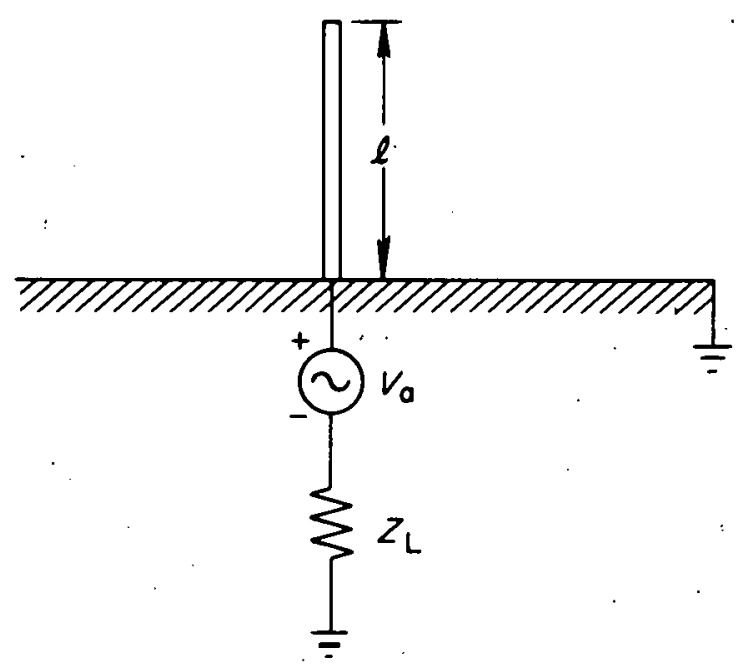

(a) THEVENIN EQUIVALENT CIRCUIT WITH THE ANTENNA IMPEUANCE PROVIDED BY THE ANTENNA.

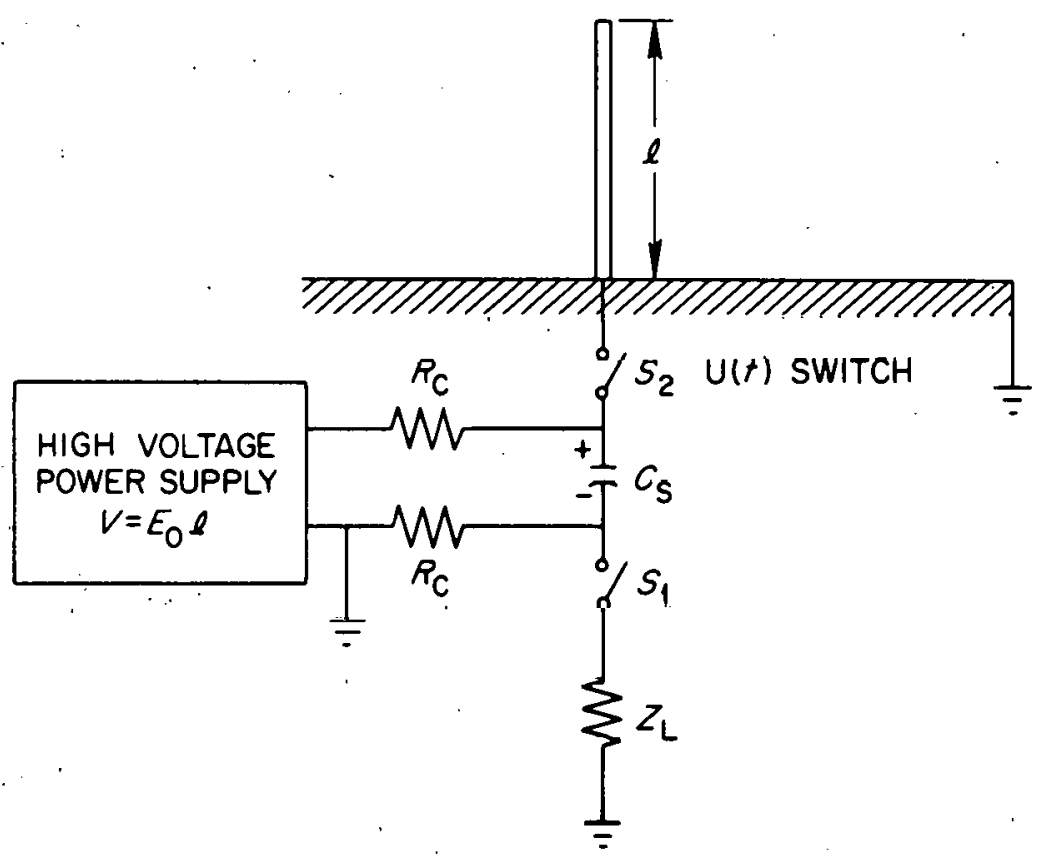

(b) THE SOURCE CAPACITOR $C_{S}$ AND SWITCH $S_{2}$ SIMULATE THE THEVENIN EQUIVALENT VOLTAGE SOURCE.

Fib. 9. Pulser that Employs the Antenna to simulate its Response to a Step-Function EMP. 
frequency domain singularity expansion. 'When this method is applied to the dipole antenna, it was found that the response can be represented by a sum of decaying exponentials and exponentially damped sinusoids.

The short-circuit current response of the dipole antenna to a stepfunction incident EMP was found to be a sum of exponentially damped sinusoids. The inverse time constants of the exponentials and the anglilar frequencies of the sinusoids were found to be functions of the dipole structure whereas the amplitude of the damped sinusoids are functions of both the structure and the incident wave.

For the double exponential EMP, the short-circuit dipole current response was found to be the short-circuit dipole current response to a step-function incident wave with the amplitudes of the sinusoids altered plus an additional current with the same time history as that of the incident waveform. The amplitudes of the damped sinusoids and the double exponential currents are functions of the dipole structure, the incident field amplitude, and the inverse time constants of the incident waveform.

An approximate formula to calculate the natural resonance frequencies of the currents on a thin cylindrical dipole excited by a unit step function voltage source across àn infinitesimal gap has been used to approximate the dipole admittance by simple polynomials. This method gives reasonable results at low frequencies and at the first several odd numbered dipole resonant frequencies. With the expressions for the antenna admittance and short-circui.t. current, the open-circuit voltage and load current and voltage responses can be calculated.

A first-order solution for the dipole effective length was derived. The open-circuit dipole voltage is the convolution of the effective length with the incident electric field. A first-order solution for the open-circuit voltage with the antenna oriented for maximum reception was found to be the product of the incident electric field times the equivalent length of the dipole plus the first partial time derivative of the incident electrir field times a constant called $\ell_{e}{ }^{\circ}$ This constant $\ell_{e}$ is determined by the antenna parameters.

The transient load response to a step-function EMP for a matched bandpass load with a narrow bandwidth centered about the dipole's first resonant frequency was discussed. It was found that for the half-length 
of the dipole equal to a quarter wavelength of the operating frequency (the bandpass center frequency) the induced current and voltage peaks are inversely proportional to the operating frequency. Also, it was found that the energy. received by the load during the first half cycle is inversely proportional to the operating frequency cubed.

Simple pulser circuits to simulate the dominant portion of the halfdipole response to. EMP have been developed from the singularity expansion solution for the dipole response and the Thevenin equivalent circuit for an antenna. The lumped-circuit pulser simulates one mode of the antenna response while the second pulser, a charged cable pulser, simulates several modes for a half cycle. The third pulser circuit employs the antenna's own impedance and simulates several modes of the antenna response for several cycles.

As an extension to this work, one could attempt to derive and apply a more accurate singularity expansion solution of the antenna admittance for both the infinitesimal and finite gaps. Also, more complicated antenna structures could be considered.

\section{ACKNOWLEDGMENTS}

I wish to thank Dr. Fred M. Tesche of the Dikewood Corporation for his interest and technical assistance regarding this work and both Judy Snow and Ruby N. Thurmer of ORNL for typing the manuscript.i In .. addition, thanks go to Dr. James H. Marable of ORNL, Dr. Carl Baum of the Air Force Weapons Laboratory, Dr. Chen To Tai of the University of Michigan, and Dr. S. W. Lee of the University of Illinois for their interest and helpful suggestions concerning this work. 


\section{REF ER ENCES}

1. R. W. King, The Theory of Linear Antennas, Harvard University Press, 1959, Chapter 2, pp. 446 and 496.

2. R. F. Harrington, Field Computation by Moment Methods, MacMillan, 1968.

3. Carl E. Baum, Interaction Note 88, "On the Singularity Expansion Method for the Solution of Electromagnetic Interaction Problems," December 1971.

4. Fred M. Tesche, Interaction Note 102, * "On the Singularity Expansion Method as Applied to the Electromagnetic scattering from ThinWires," April 1972.

5. S. W. Lee and B. Leung, Interaction Note 96, * "The Natural Resonance Frequency of a Thin Cylinder and Its Application to. EMP Sutides," February 1972.

6. Carl E. Baum, Sensor and Simulation Note 38,* "Parameters for Some Electrically Small. Electromagnetic Sensors," 21 March 1967.

7. Fred M. Tesche, Private Communications, "On the Singularity Expansion Method as Applied to the Electromagnetic Scattering from Thin-Wires," 8 May 1972.

8. Chen-To Tai, Private Communications, 6 June 1972.

9. R. W. P. King and C. W. Harrison, Jr., Antennas and Waves - A Modern Approach, The M.I.T. Press, 1969, Chapter 3.

10. David B. Nelson, Effects of Nuclear EMP on AM Radio Broadcast Stations in the Emergency Broadcast System, ORNL-TM-2830, January 1971.

11. P. P. Toulious et al., "Effects of EMP Environment on Military Systems," Vol. I, IITRI Proj. No. E6114, Contract No. DAAKO2-68-C0377 (MERDC), IIT Research Institure, February 1969.

12. James 'H. Marable, Private communications on the Discharge of a Transmission Line Through an Impedance, 12 september 1972.

* Interaction Notes and Sensor and Simulation Notes are published at the Air Force Weapons Laboratory, Kirtland.AFB, New Mexico. 
13. S. A. Schelkunoff, 'Concerning Hallen's Integral Equation for Cylindrical Antennas," Proceedings of the IRE, Vol. 33, pp.872878, December 1945.

14. C. H. Papas, "On the Infinitely Long Cylindrical Antenna," J. Appl. Phys., Vol. 20, pp. 437-440, May 1949.

15. T. T. Wu and R.W. P. King, "Driving Point and Input Admittance of Linear Antennas," J. Appl. Phys., Vol. 30, No. 1, pp. 74-76, January 1959. 
ORNL-TM-4086

\section{INTERNAL DISTRIBUTION}

1-13. P. R. Barnes
14. C. B. Brooks
15. C. V. Chester
16. G. A. Cristy
17. F. I. Culler
18. F. M. Glass
19. C. M. Haaland
20. C. H. Kearny
21. J. H. Marable
22. D. B. Nelson
23. G. T. Ragan

\author{
24. J.A. Russell \\ 25. J. R. Totter \\ 26. . E. P. Wigner \\ 27-29. Civil Defense Research \\ Section Library \\ 30-31. Central Research Library \\ 32: Document Reference Section \\ 33-35. Laboratory Records Department \\ 36. Laboratory Records, ORNL R.C. \\ 37. ORNL Patent Office
}

\section{EXTERINAL DISTRI BUTION}

38. Pier A.Abetti, Communications Products Plant, General Electric Company, Lynchburg, Virginia $\cdot 24505$.

39. Commander, Air Force Weapons Laboratory, AFSC, Kirtland AFB, New Mexico, 87117, ATTN: EL.

40. Commander, Air Force Weapons Laboratory, AFSC, Kirtland AFB, New Mexico 87117, ATTN: DOGL, Technical Library.

41. M/Sgt. Robert Armstrong, AFWL-ELE, Kirtland AFB, New Mexico 87117.

42-43. Carl E. Baum, AFWL/ELE, Kirtland AFB, New Mexico 87117.

44. Braddock, Dunn, and McDonald, Inc., P. O. Box 10694, El Paso, Texas 79925, ATTN: J. V. Braddock.

45. J. C. Bresee, Assistant Director for General Energy Development, Division of Applied Technology, U.S. Atomic Energy Commission, Washington, D. C. .20545.

46. William Bryson, Phelps Dodge Communications Co., Route 79, Marlboro, N. J. 07746.

47. Don B. Clark, Naval Civil Engineering Laboratory, Port Hueneme, California 93043 .

48. Communications Officer, Civil Defense Mobilization Office, 307 Locust Street, Knoxville, Tennessee.

49. John Darrah, AFWL/ELE, Kirtland AFB, New Mexico 87117.

50. The Dikewood Corporation, 1009 Bradbury Drive, S.E., University Research Park, Albuquerque, New Mexico 87106.

51. John Dixon, Kentucky Utilities. Co., 120 S..Lime, Lexington, Kentucky.

52. LTC. Don Dowler, AFWL/ELE, Kirtland AFB, New Mexico 87117.

53-59. George Dunham, Office of Emergency Preparedness, P. 0. Box 1293, Albuquerque, New Mexico 87103.

60. William :Emberson, IIT, Research Institute, 10 West 35 th street, Chicago, Illinois 60616. 
61. J. F. Fischer, Fischer Custom Communications, P. 0. Box 58I, Manhattan Beach, California 90266.

62. Larry Fowler, . AFWL/ELE, Kirtland AFB, New Mexico 87117.

63. IIT Research Institute, 10 west 35 th street, Shicago, Illinois 60616, ATTM: J. E. Bridges, Engr. Advisor.

64. Raj.Mi.tra., Dept. of Electrical Engineering, University of Illinois, Urbana, Illinois 61801.

65. Kelvin Lee., The Dikewood Corporation, Westwood Research Branch, Suite.850.,..1100.Clendon Avenue, Los Angeles,. California 90024.

66. Col. Robert Nine, AFWL/ELE, Kirtland AFB, New Mexico 87117.

67. John Portasik, AFWL/ELE, Kirtland AFB, New Mexico 87117.

68. Ren F. Reed, Defense Civil Preparedness Agency, Secretary of Defense, The Pentagon, Washington, D. C. 20310.

69. Harry E. Roderick, Defense Civil Preparedness Agency, Secretary of...Defense, The Pentagon, Washington, D. C. 20310.

70. .Bruce Sanderson, AHWL/ELE, Kirtiand AFB, New Mexico 8\%11\%.

7i?. Chen-To Tai, University of Michigan, The Radiation Laboratory, 2216. Space. Research Building, 2455 Haywood' St., Ann Arbor, Michigan 48105.

72. Clay..Taylor, ...Dep.t. of Electrical Engineering, Mississippi state University, Mississippi. State, Mississippi 37962.

73-74. Technical. Information Center, Oak Ridge, Tennessee 37830.

75. U.S. . Army. Materiel ...Command, .. Harry.. Di.amond Laborator.i.es., ... Washing.ton, D. C., 20430, ATTN: R. Buslak.

76. Commanding General, U.S. Army S.trategic Communications Command, Fort. Hauchuca, Arizone 85613, ATTN: SCCOP-1.

77. Robert.J. Walz, Motorola Communications and Electronics, Inc., .1201.E. Algonguin, Schaumburg, Illinois 60172.

78. Director, Weapons Sys.tems Evaluation Group, ODDRE, Office, Secretary of Defense, 400 Army-Navy Drive, Washington, D. C. 20305, ATTN: H. A. Knapp, Jr.

79. Doug. Wilson, AFWL/ELE, Kirtland.AFB, New Mexico 87117.

80. Research and Technical Support Division, AEC, ORO.

81: Patent Orfice, AEC, ORO. 
OAK RIDGE NATIONAL LABORATORY

OPERATED BY

UNION CARBIDE CORPORATION

NUCLEAR DIVISION

\section{CARABDive}

POST OFFICE BOX $X$

OAK RIDGE, TENNESSEE 37830

\section{SPECIAL 4TH CLASS RATE BOOKS}

